\title{
Fuzzy Semiactive Vibration Control of Structures Using Magnetorheological Elastomer
}

\author{
Xuan Bao Nguyen,, Toshihiko Komatsuzaki, ${ }^{2}$ Yoshio Iwata, ${ }^{2}$ and Haruhiko Asanuma \\ ${ }^{1}$ Graduate School of Natural Science and Technology, Kanazawa University, Kakuma-machi, Kanazawa, Ishikawa 920-1192, Japan \\ ${ }^{2}$ Institute of Science and Engineering, Kanazawa University, Ishikawa, Japan \\ Correspondence should be addressed to Xuan Bao Nguyen; xuanbao233@gmail.com
}

Received 9 August 2016; Revised 26 December 2016; Accepted 15 January 2017; Published 9 February 2017

Academic Editor: Mahmoud Bayat

Copyright (c) 2017 Xuan Bao Nguyen et al. This is an open access article distributed under the Creative Commons Attribution License, which permits unrestricted use, distribution, and reproduction in any medium, provided the original work is properly cited.

In this research, a novel variable stiffness vibration isolator that uses magnetorheological elastomers (MREs) accompanied with a fuzzy semiactive vibration control was developed. Firstly, the viscoelastic characteristics of MREs in shear mode were clarified systematically in order to achieve a mathematical basis for the controller development. Secondly, the fuzzy semiactive vibration control with a strategy based on the Lyapunov theory and dynamic characteristic of MREs was proposed for minimizing the movement of the isolator. In the conventional semiactive algorithm, the command applied current of MRE-based isolator is set at either minimum or maximum value which causes high acceleration and jerk peaks periodically, thus leading to the degeneration of the overall system quality. However, the fuzzy semiactive algorithm presented here is able to produce the sufficient applied current and thus viscoelastic force is desirably produced. The effectiveness of the developed isolator was evaluated numerically by MATLAB simulation and experimentally in comparison with the performances of a passive system and a system with on-off type semiactive controller. The results showed that the developed controller was successful in overcoming the disadvantages of conventional on-off semiactive control.

\section{Introduction}

A semiactive vibration control device is basically a system whose mechanical properties change in response to external physical stimuli. Consequently, system properties such as stiffness and damping change and structural vibration can be suppressed at a particular frequency. Furthermore, development of the magnetorheological (MR) material has provided a tradition for enhancing the advantages of these devices in terms of variable damping and/or stiffness with less power consumption, low cost, and more efficiency compared with traditional active control devices. MR materials have been classified into three specific catalogues: fluids, foams, and elastomers [1]. MR fluids (MRFs) are well known in various fields, such as automotive industry, civil engineering, and construction vehicles. However, MRFs exhibit disadvantages; for example, deposition and sealing problems exist in mechanical element installation [2]. In contrast, MR elastomers (MREs), used in semiactive control, have recently emerged as a smart material that could potentially improve traditional systems in controlling structural vibrations [3].

MREs are the solid analogs [4] to MRFs and are classified into isotropic and anisotropic MREs according to their curing processes. While anisotropic MREs are cured in magnetic fields, isotropic MREs are cured without the presence of a magnetic field. Devices that use MREs can work in multiple degrees of freedom (DOFs). MRE can either strain or shear through its longitudinal or lateral axis, respectively. On the other hand, devices that use MRFs only work in single DOF because an MR damper must retract and extend through its longitudinal axis [5]. In addition, MRF devices work in postyield areas and mainly possess tunable damping, but MRE devices work in preyield areas and possess tunable stiffness. Because of variable stiffness, MRE devices can efficiently alter natural frequencies. Consequently, MREs have attracted much interest in the application to intelligent devices, such as vibration absorbers and isolators. 
Vibration absorbers (VAs) have been developed to attenuate structural vibration. A traditional VA, called a passive VA, only works effectively if the frequencies of excitation are in their designed narrow band. In contrast, a VA that uses an MRE, called an adaptive-tuned vibration absorber (ATVA), is capable of adjusting the working frequency band according to the frequency of excitation in real time so that the vibrations are absorbed for a wider frequency range. For example, Komatsuzaki and Iwata [6] introduced an MRE of $40 \%$ iron volume content (vol\%) in ATVAs in order to mitigate the vibrations of a single DOF with a frequency range of 25.8-36 Hz. In addition to the application in ATVAs, MREs are also applied to vibration isolators (VIs) used to isolate the vibration source. Similar to passive VAs, passive VIs work well in narrow designed bands. However, MRE-based VIs possess controllable stiffness whose isolation frequency can be adjusted in real time. For example, Liao et al. [7] developed an MRE-based VI where real-time semiactive vibration control techniques are applied in order to reduce vibration in the structure. The transmissibility of the payload near the resonant frequency decreased by $61.5 \%$ compared with the passive systems. The root-mean-square (RMS) values of the displacement and velocity responses also decreased significantly by $36 \%$ and $45.4 \%$, respectively.

In order to achieve a desirable working frequency, an MRE-based device should employ a controller. We need to establish an algorithm to control MRE stiffness by changing the magnetic field intensity. Numerous semiactive control algorithms, such as clipped-optimal control [8], linear-quadratic-Gaussian (LQG) controller [9], fuzzy logic control [10], Lyapunov-based strategies [11], and turboLyapunov controller [12], have been introduced to control MRF dampers. However, there are not many control algorithms on the application of MRE devices (to the best of our knowledge); the sinusoidal and random responses of 1DOF and 2-DOF systems have shown that stiffness on-off control systems using MRE isolated vibration efficiently [7]. Switching between minimum and maximum MRE stiffness has been implemented based on input displacement $(x)$ and velocity $(\dot{x})$. However, this control algorithm is discrete and, consequently, prone to inducing chatter around the switching point (i.e., when either $x$ or $\dot{x}$ becomes zero), especially in the case of fast dynamics. Furthermore, fast switching produces periodical acceleration and jerk peaks that result in negative effects on the quality of devices.

In this study, the fuzzy semiactive controller is introduced for switching MRE property in order to overcome the disadvantages of conventional control algorithm. Firstly, the dynamic viscoelastic characteristics of MREs such as the dependence of dynamic stiffness, dynamic damping coefficient, and dynamic force-displacement response on the excitation frequency, excitation amplitude, and magnetic flux density are presented. Secondly, a fuzzy semiactive control strategy based on these characteristics and Lyapunov theory is developed. The effectiveness of this controller is proved numerically by MATLAB simulation. Furthermore, the realtime vibration control of a 1-DOF system that uses the fuzzy semiactive controller is performed in an experiment. The experimental results show that RMS acceleration, RMS displacement, and chatter are all reduced, and the device with the proposed control strategy also works more efficiently than those with the on-off switching control.

\section{MRE Fabrication and Viscoelastic Property}

2.1. MRE Fabrication. Fabricated MRE samples consist of RTV silicon rubber (Shin-etsu KE1416), silicon oil, and iron particles (BASF SG-BH) with average diameter of $20 \mu \mathrm{m}$. The materials were then placed in a mixer in order for the mixture to become homogenous. The mixture was placed in a copper mold and compressed to remove air bubbles. Finally, the mixture was cured under a magnetic field of $0.5 \mathrm{~T}$ at room temperature for 24 hours. An anisotropic elastomer sample was formed in square cuboids of sides $25 \mathrm{~mm}$, thickness $10 \mathrm{~mm}$, and iron content of $40 \mathrm{vol} \%$ (Figure 1(a)).

2.2. Experimental Setup. The viscoelastic properties of the MRE samples were investigated by a system shown in Figure 1(b). In this system, two MREs worked as system springs/dampers, and they were placed between the iron cores of an electromagnet. While the lower core was installed on a base exposed to excitation, the upper core was fixed along with a load sensor. The base was excited by a shaker (EMIC Corp. Model 371-A) whose excitation signal was supplied by a signal generator and a power amplifier (EMIC Corp. Model 371-A). The displacement of the base and upper core's force were measured by using a laser displacement sensor (KEYECE LB-02) and a load sensor (PCB PIEZOTRONICS 208C02), respectively. The force-displacement response was processed by a Fast Fourier Transform (FFT) spectrum analyzer (ONOSOKI CF-5220Z). A direct current (DC) power supply (TAKASANGO ZX-400LA) provided adjustable DC current to a magnetic coil. In dynamic tests, numerous experiments were implemented for various harmonic inputs. The excitation frequency was adjusted from $1 \mathrm{~Hz}$ to $30 \mathrm{~Hz}$, excitation amplitude was changed from $0.4 \mathrm{~mm}$ to $1.4 \mathrm{~mm}$, and applied current was driven from $0 \mathrm{~A}$ to $6 \mathrm{~A}$ (magnetic flux density was adjusted from $0 \mathrm{mT}$ to $326 \mathrm{mT}$ ).

In this investigation, the viscoelastic properties of the MRE sample were followed by the definition in [13]. For harmonic excitation, the equivalent stiffness, $K$, and the damping coefficient, $C$, are defined by the following equations:

$$
\begin{aligned}
& K=\frac{F_{0}}{x_{0}}, \\
& C=\frac{E}{F_{0} x_{0}}, \\
& E=\int_{0}^{T} F x d t .
\end{aligned}
$$

In (1), $F_{0}$ represents the force amplitude, $x_{0}$ is the displacement amplitude, and the equivalent stiffness $K$ is defined as the ratio between these two amplitudes, as illustrated in Figure 2(a). The damping coefficient is defined as the ratio between the dissipated energy $E$ and the work done by the external force $F_{0} x_{0}$ per cycle, as illustrated in Figure 2(b). The energy dissipated by viscous element is calculated by (3), 


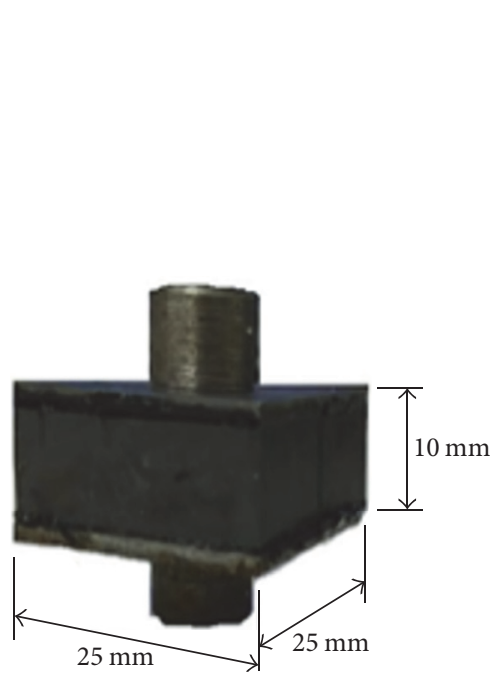

(a)

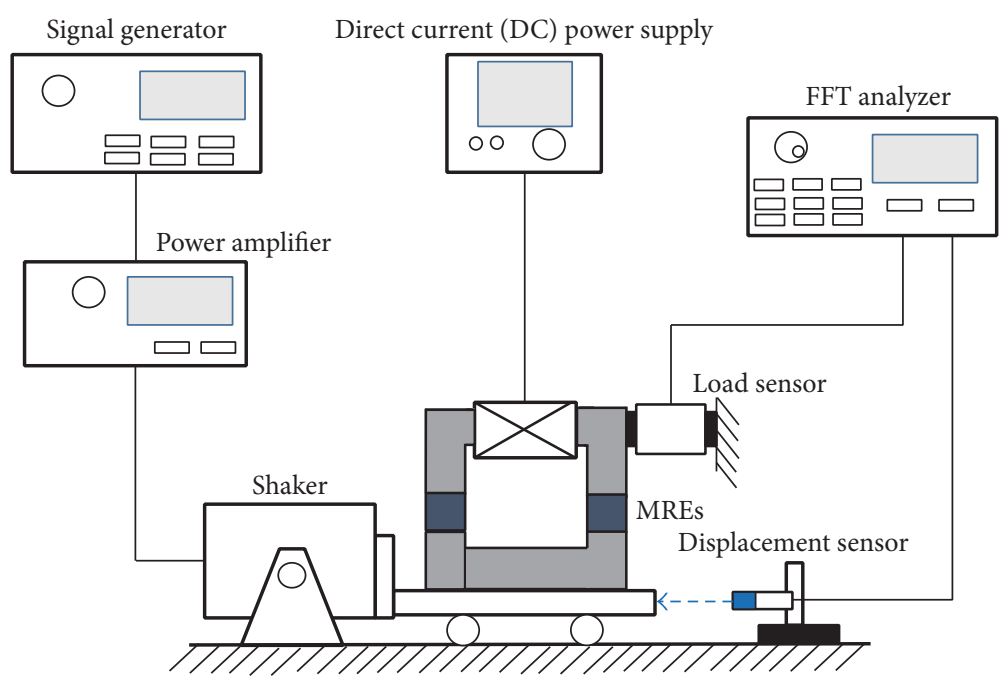

(b)

FIGURE 1: MRE and its viscoelastic property measurement system: (a) the MRE sample (b) and the schematic of the system.

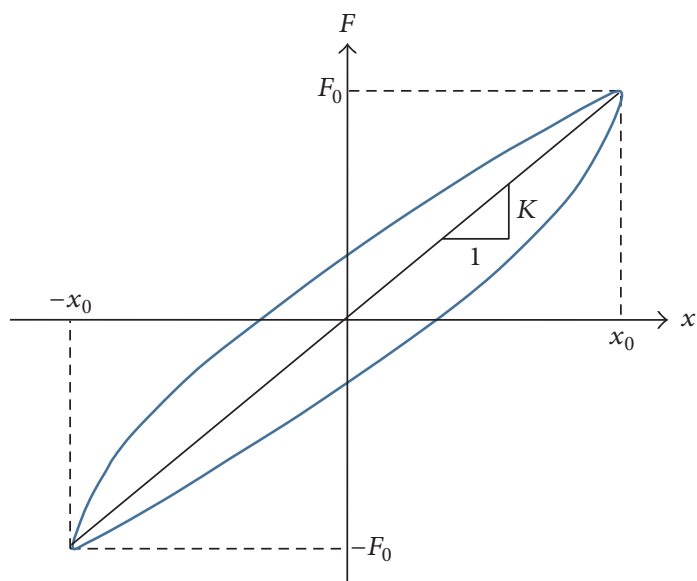

(a)

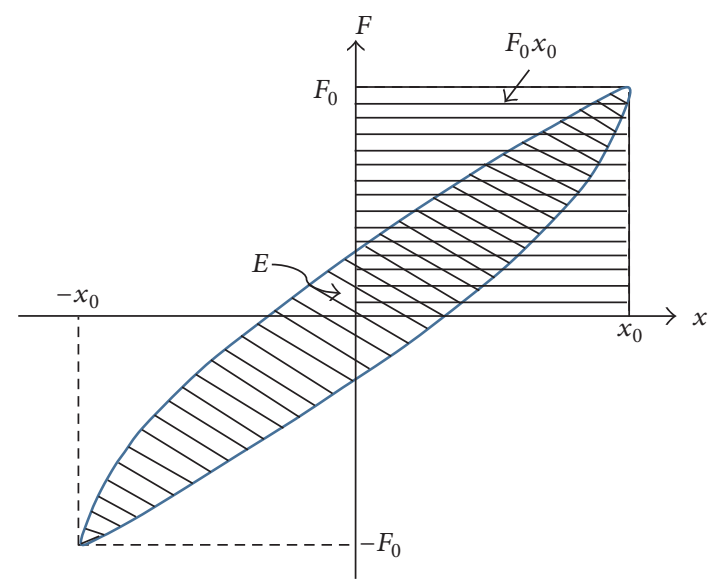

(b)

Figure 2: Definition of equivalent stiffness $(K)$ and damping coefficient $(C)$ : (a) the equivalent stiffness $K$; (b) the damping coefficient $C$ is defined as the ratio between the dissipated energy $E$ and the work done by the external force $F_{0} x_{0}$ per cycle.

where $F$ is the force induced in MRE as a function of $x$, and $T$ is the period of oscillation.

\subsection{Experimental Testing of MRE Property}

2.3.1. Frequency Dependence. Firstly, frequency dependence of the MRE properties was investigated. The base excitation amplitude $x_{0}$ was set to $0.75 \mathrm{~mm}$, and the excitation frequency $f$ was increased from $1 \mathrm{~Hz}$ to $30 \mathrm{~Hz}$. Three levels of electric currents, $0 \mathrm{~A}, 2 \mathrm{~A}$, and $4 \mathrm{~A}$, which corresponded to the magnetic field strength of $0 \mathrm{mT}, 213 \mathrm{mT}$, and $267 \mathrm{mT}$, were applied.

The experimental results are shown in Table 1 and in Figures 3 and 4 . Figure 3 shows the equivalent stiffness $K$ and damping coefficient $C$ to the excitation frequency with different currents (magnetic field intensities). The equivalent stiffness and damping coefficient increased monotonically with the increase in frequency. The equivalent stiffness showed an exponential increment up to the frequency of $7 \mathrm{~Hz}$. Beyond $7 \mathrm{~Hz}$, the equivalent stiffness increased insignificantly by increasing the excitation frequency. The damping coefficient slightly increased by the increment of frequency. The same trend was observed for different levels of current. Figure 4 shows force-displacement response under harmonic excitations. It is obvious that the slope of hysteresis loop and the area of each loop were increased with the increase in both variables: frequency and current.

2.3.2. Amplitude Dependence. The dependence of the stiffness, damping coefficient, and force-displacement responses 
TABLE 1: Equivalent stiffness and damping coefficient versus excitation frequencies for different applied currents with excitation amplitude $x_{0}=0.75 \mathrm{~mm}$.

\begin{tabular}{|c|c|c|c|c|c|c|}
\hline \multirow{2}{*}{ Frequency } & \multicolumn{2}{|c|}{$0 \mathrm{~A}$} & \multicolumn{2}{|c|}{$2 \mathrm{~A}$} & \multicolumn{2}{|c|}{$4 \mathrm{~A}$} \\
\hline & $K(\mathrm{~N} / \mathrm{mm})$ & $C(\mathrm{Ns} / \mathrm{m})$ & $K(\mathrm{~N} / \mathrm{mm})$ & $C(\mathrm{Ns} / \mathrm{m})$ & $K(\mathrm{~N} / \mathrm{mm})$ & $C(\mathrm{Ns} / \mathrm{m})$ \\
\hline $1 \mathrm{~Hz}$ & 13.2 & 0.79 & 23.0 & 0.82 & 27.9 & 0.92 \\
\hline $3 \mathrm{~Hz}$ & 14.2 & 0.79 & 26.0 & 0.81 & 31.3 & 0.90 \\
\hline $6 \mathrm{~Hz}$ & 15.1 & 0.81 & 27.6 & 0.87 & 33.4 & 0.93 \\
\hline $9 \mathrm{~Hz}$ & 15.6 & 0.82 & 28.5 & 0.92 & 34.6 & 0.97 \\
\hline $12 \mathrm{~Hz}$ & 16.1 & 0.83 & 29.0 & 0.95 & 35.1 & 1.0 \\
\hline $15 \mathrm{~Hz}$ & 16.4 & 0.86 & 29.5 & 0.98 & 35.6 & 1.03 \\
\hline $18 \mathrm{~Hz}$ & 17.0 & 0.90 & 29.9 & 1.08 & 35.7 & 1.11 \\
\hline $22 \mathrm{~Hz}$ & 17.5 & 0.92 & 30.6 & 1.12 & 36.2 & 1.18 \\
\hline $26 \mathrm{~Hz}$ & 17.9 & 0.94 & 31.6 & 1.13 & 37.3 & 1.21 \\
\hline $30 \mathrm{~Hz}$ & 18.0 & 0.96 & 32.3 & 1.14 & 37.5 & 1.21 \\
\hline
\end{tabular}

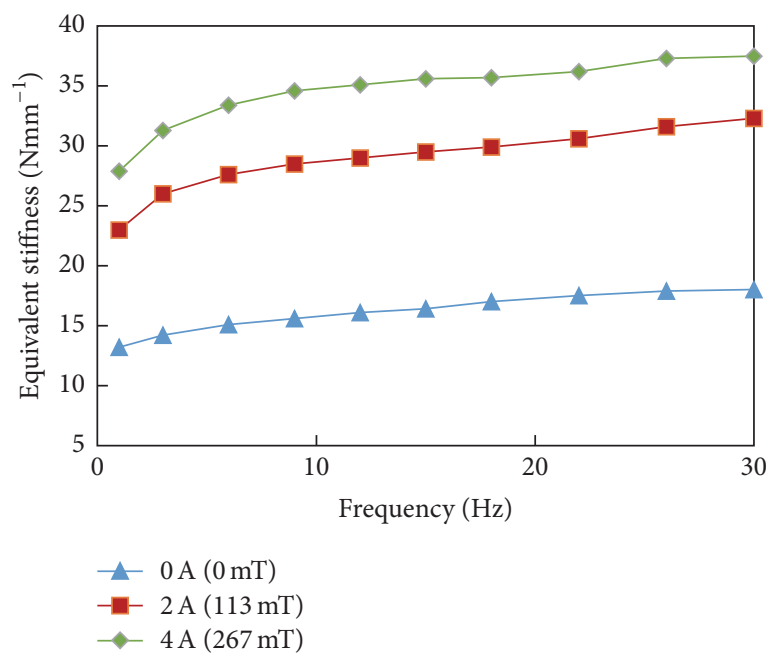

(a)

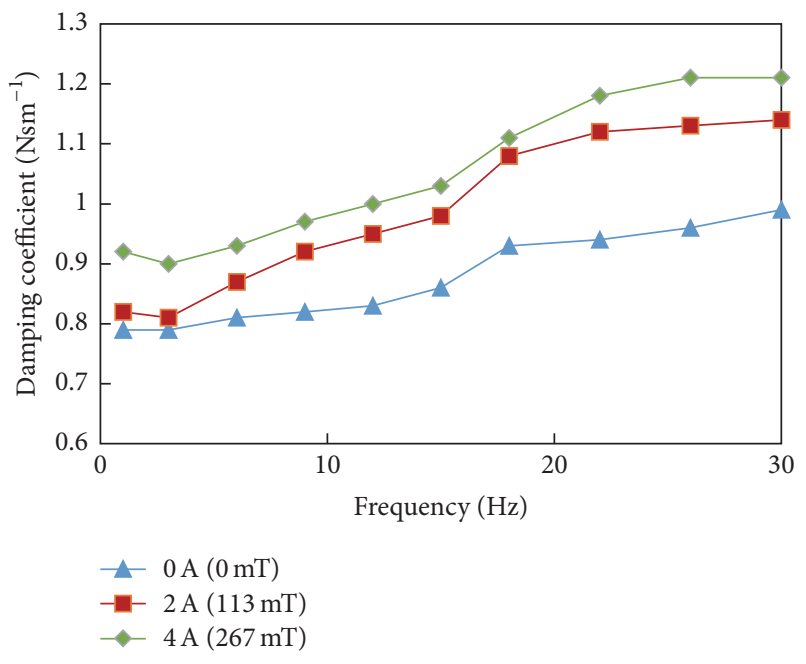

(b)

FIGURE 3: Stiffness and damping properties versus excitation frequency for different applied currents with excitation amplitude $x_{0}=0.75$ mm: (a) the equivalent stiffness $K$ and (b) the damping coefficient $C$.

on excitation amplitude were also studied experimentally. In these experiments, the excitation frequency was fixed at $15 \mathrm{~Hz}$, and the excitation amplitude $x_{0}$ was changed from $0.4 \mathrm{~mm}$ to $1.4 \mathrm{~mm}$. The experiment was conducted under three different currents of $0 \mathrm{~A}, 2 \mathrm{~A}$, and $4 \mathrm{~A}$.

The equivalent stiffness and damping coefficient are shown in Table 2 in Figure 5, and the force-displacement responses are shown in Figure 6. Figure 5 depicts that the equivalent stiffness decreased when the excitation amplitude increased, and the rate of this trend also increased with the increase in the current magnitude. In contrast, the change in damping coefficient was proportional to the change in excitation amplitude. In contrast to the case of frequency dependence, the slopes of hysteresis loop decreased with increase in amplitude and this trend was the same for all values of applied current. The higher applied current provides the higher area of this closed loop (Figure 6).
2.3.3. Magnetic Field Dependence. The effect of magnetic field strength on the change of stiffness and damping properties was further evaluated. The experiments were carried out with $0.75 \mathrm{~mm}$ amplitude and with three different excitation frequencies of $1 \mathrm{~Hz}, 15 \mathrm{~Hz}$, and $30 \mathrm{~Hz}$, respectively. The magnetic flux density was increased from $0 \mathrm{mT}$ to $326 \mathrm{mT}$, which corresponded to the electric current from $0 \mathrm{~A}$ to $6 \mathrm{~A}$.

The experimental results are shown in Table 3 and in Figures 7 and 8. As shown in Figure 7(a), the equivalent stiffness increased sharply for the magnetic field ranging from $0 \mathrm{mT}(0 \mathrm{~A})$ to $173 \mathrm{mT}(4 \mathrm{~A})$, and the value gradually became large until it reached the saturated state when the magnetic field intensity was $365 \mathrm{mT}$ (6 A). The damping coefficient in Figure 7(b) showed a slight fluctuation when magnetic flux density increased, especially when the $30 \mathrm{~Hz}$ excitation frequency was given, but the value in overall increased gradually with the increase in magnetic flux density 


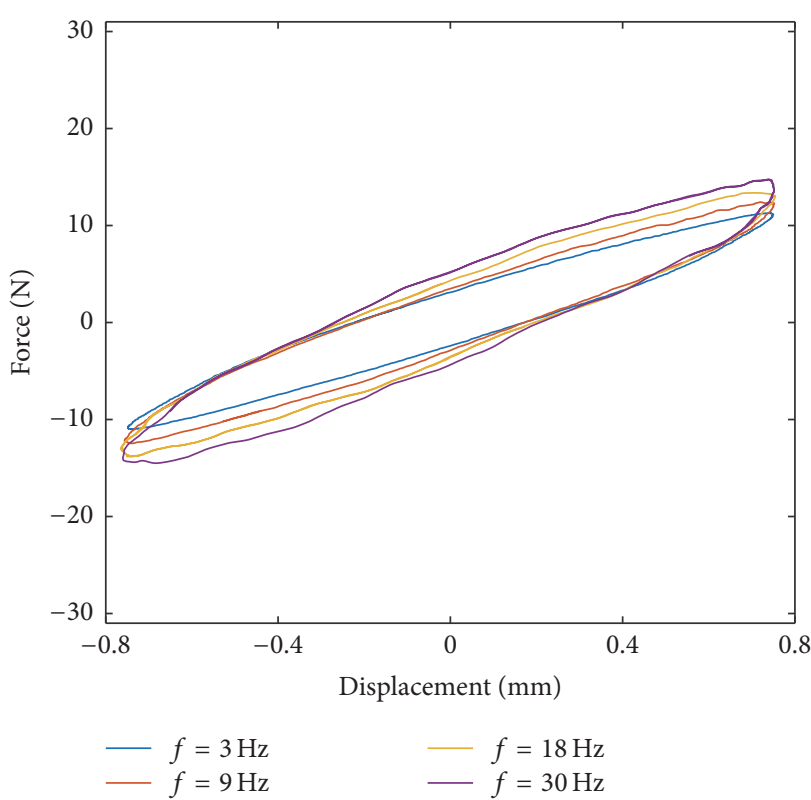

(a)

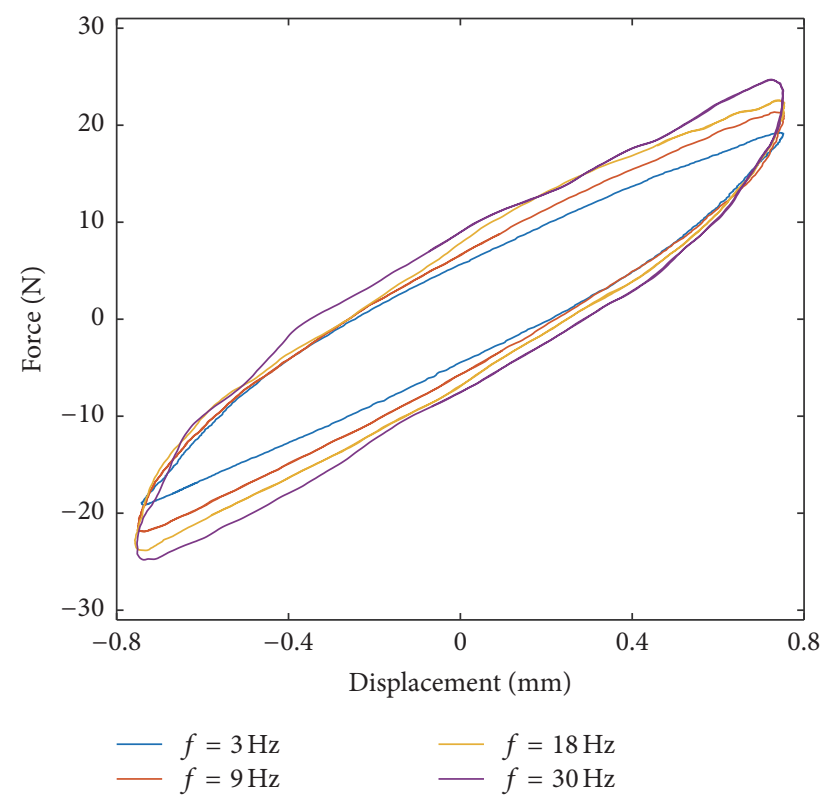

(b)

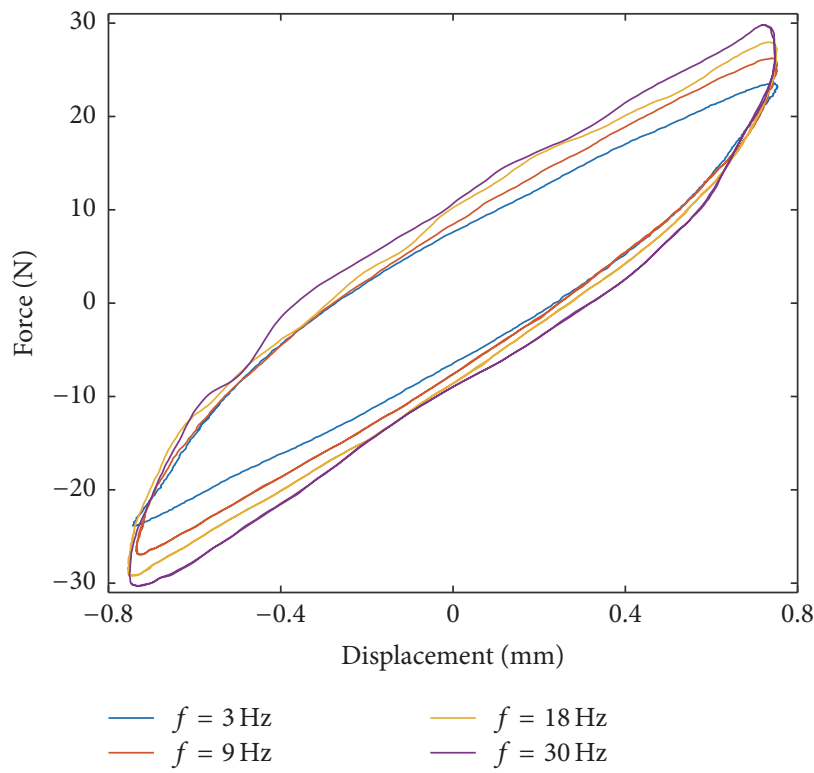

(c)

FiguRE 4: Force-displacement response under different frequencies with excitation amplitude $x_{0}=0.75 \mathrm{~mm}$ : (a) $I=0 \mathrm{~A}(0 \mathrm{mT}),(\mathrm{b}) I=2 \mathrm{~A}$ $(218 \mathrm{mT})$, and $(\mathrm{c}) I=4 \mathrm{~A}(267 \mathrm{mT})$.

TABLE 2: Equivalent stiffness and damping properties versus excitation amplitudes for different levels of applied current with excitation frequency $f=15 \mathrm{~Hz}$.

\begin{tabular}{|c|c|c|c|c|c|c|}
\hline \multirow{2}{*}{ Amplitude } & \multicolumn{2}{|c|}{$0 \mathrm{~A}$} & \multicolumn{2}{|c|}{$2 \mathrm{~A}$} & \multicolumn{2}{|c|}{$4 \mathrm{~A}$} \\
\hline & $K(\mathrm{~N} / \mathrm{mm})$ & $C(\mathrm{Ns} / \mathrm{m})$ & $K(\mathrm{~N} / \mathrm{mm})$ & $C(\mathrm{Ns} / \mathrm{m})$ & $K(\mathrm{~N} / \mathrm{mm})$ & $C(\mathrm{Ns} / \mathrm{m})$ \\
\hline $0.4 \mathrm{~mm}$ & 20.2 & 0.48 & 33.1 & 0.58 & 43.9 & 0.62 \\
\hline $0.6 \mathrm{~mm}$ & 18.4 & 0.63 & 29.3 & 0.76 & 38.5 & 0.8 \\
\hline $0.8 \mathrm{~mm}$ & 17.7 & 0.77 & 27.7 & 0.93 & 34.4 & 0.99 \\
\hline $1.0 \mathrm{~mm}$ & 16.9 & 0.96 & 26.3 & 1.12 & 32.2 & 1.20 \\
\hline $1.2 \mathrm{~mm}$ & 16.4 & 1.1 & 24.8 & 1.33 & 29.9 & 1.41 \\
\hline $1.4 \mathrm{~mm}$ & 15.9 & 1.28 & 24.1 & 1.52 & 28.6 & 1.56 \\
\hline
\end{tabular}




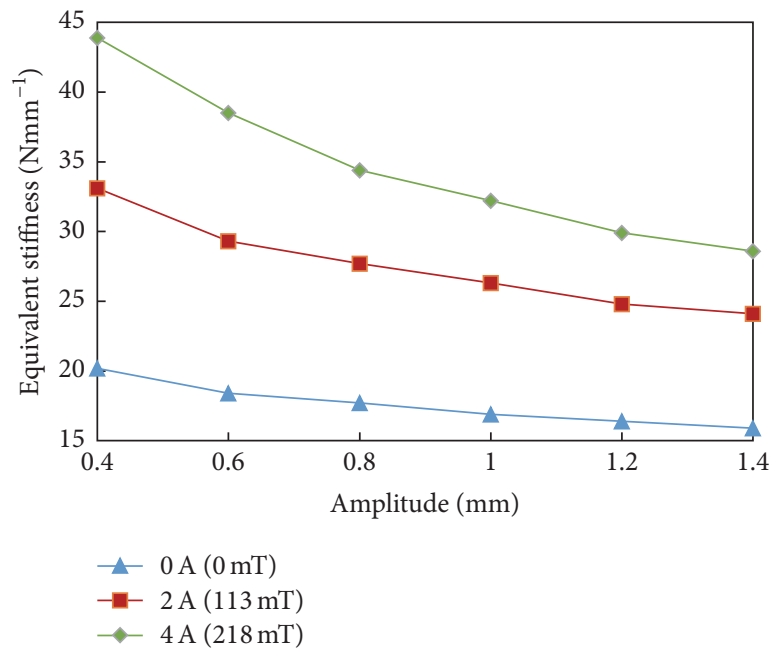

(a)

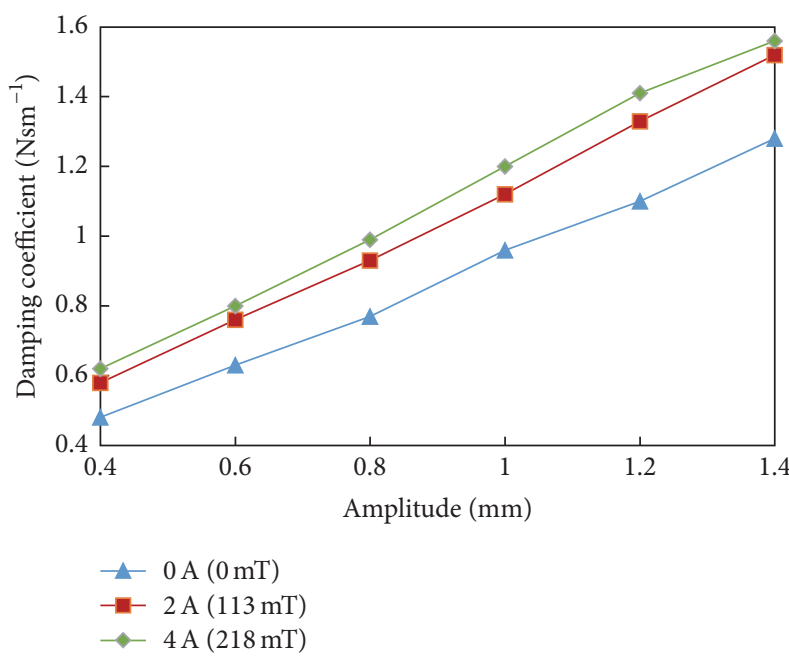

(b)

FIGURE 5: Stiffness and damping properties versus excitation amplitude for different levels of applied current with excitation frequency $f=$ $15 \mathrm{~Hz}$ : (a) the equivalent stiffness $K$ and (b) the damping coefficient $C$.

TABLE 3: Equivalent stiffness and damping propertiesversus applied currents (magnetic flux density) for different frequencies with excitation amplitude $x_{0}=0.75 \mathrm{~mm}$.

\begin{tabular}{lcccccc}
\hline $\begin{array}{l}\text { Applied current (magnetic } \\
\text { flux density) }\end{array}$ & \multicolumn{2}{c}{$1 \mathrm{~Hz}(\mathrm{~N} / \mathrm{mm})$} & $C(\mathrm{Ns} / \mathrm{m})$ & $K(\mathrm{~N} / \mathrm{mm})$ & $C(\mathrm{Ns} / \mathrm{m})$ & \multicolumn{2}{c}{$30 \mathrm{~Hz}$} \\
\hline 0 A $(0 \mathrm{mT})$ & 14.2 & 0.76 & 18.2 & 0.85 & 19.7 & 0.98 \\
1 A (59 mT) & 17.6 & 0.81 & 22.6 & 0.92 & 24.5 \\
2 A (113 mT) & 22.5 & 0.83 & 29.5 & 0.97 & 31.8 \\
3 A (167 mT) & 25.1 & 0.87 & 32.6 & 1.01 & 35.1 \\
4 A (218 mT) & 27.4 & 0.90 & 35.6 & 1.03 & 37.0 \\
5 A (267 mT) & 28.6 & 0.88 & 36.1 & 1.01 & 37.9 & 1.12 \\
6 A (316 mT) & 29.2 & 0.87 & 37.0 & 1.01 & 38.7 \\
\hline
\end{tabular}

until it reached saturation. Figure 8 shows the change of force-displacement loci in the studied range of magnetic flux density. The slope and area of this closed loop increased for higher magnetic flux density. Since the area enclosed by loop corresponds to the dissipated energy by MRE isolator, the loss of energy was found to increase when the magnetic flux density increases.

\section{On-Off and Fuzzy Control Algorithms of MRE Isolator}

In this study, MRE stiffness was found to increase steadily when the applied current changed from $0 \mathrm{~A}$ to $4 \mathrm{~A}$ and increased slightly when the applied current reached higher than $4 \mathrm{~A}$, as shown in Figure 7(a). The range of low to high stiffness was limited by the lower and upper bounds of the applied current, which correspond to $0 \mathrm{~A}$ and $4 \mathrm{~A}$, respectively. Since the change of the damping coefficient in response to the applied current was insignificant (Figure 7(b)), it is reasonable to assume that this coefficient is unchanged when applied current is varied.
3.1. Dynamics Model of 1-DOF System. The mathematical model of a 1-DOF vibration system is shown in this subsection. The motion equation for the 1-DOF system shown in Figure 9 is described in time domain as

$$
m \ddot{x}+c \dot{x}+k^{*} x=c \dot{u}+k u \text {. }
$$

In (4), $x$ represents the displacement of mass $m, u$ is the displacement of the ground base, $c$ is the MRE damping coefficient, $k^{*}=k_{0}+\Delta k$ is the tunable MRE stiffness, $k_{0}$ is the minimum stiffness which is obtained without applied current, and $\Delta k$ is the increment stiffness when the current is applied.

Transfer function $G(s)$ of the system in Laplace domain is defined as

$$
G(s)=\frac{X(s)}{U(s)}=\frac{\left(c / k^{*}\right) s+1}{\left(m / k^{*}\right) s^{2}+\left(c / k^{*}\right) s+1} .
$$

In (5), $X(s)$ denotes the Laplace transform function of $x(t)$, and $U(s)$ is the Laplace transform function of $u(t)$. 


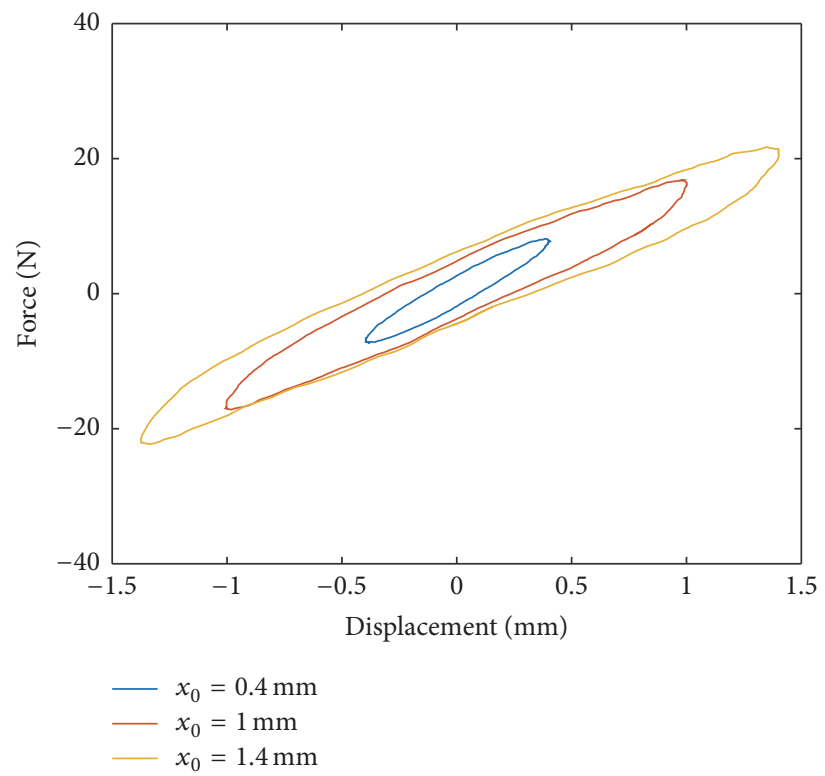

(a)

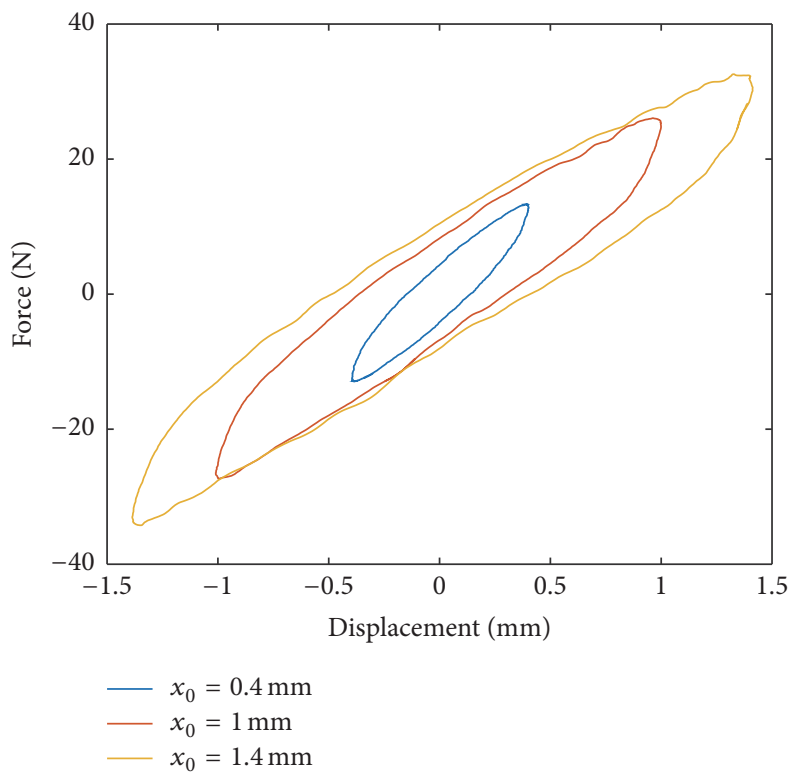

(b)

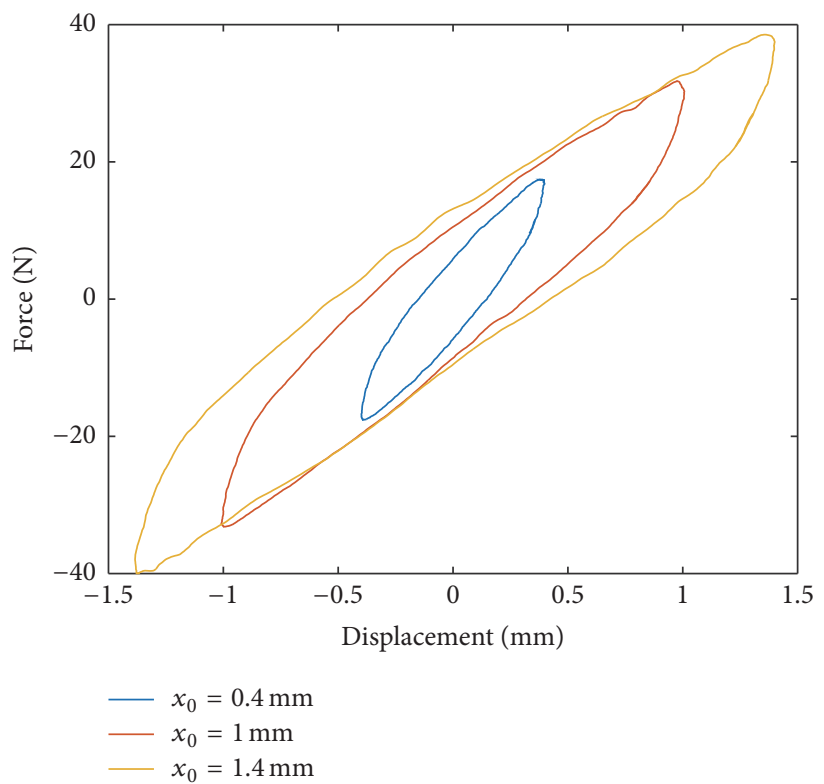

(c)

FIGURE 6: Force-displacement response under different amplitude levels with excitation frequency $f=15 \mathrm{~Hz}$ : (a) $I=0 \mathrm{~A}(0 \mathrm{mT})$, (b) $I=2 \mathrm{~A}$ $(218 \mathrm{mT})$, and $(\mathrm{c}) I=4 \mathrm{~A}(267 \mathrm{mT})$.

Displacement transmissibility $T_{R}(\omega)$ of system $G(j \omega)$ is further defined by replacing $s$ with $j \omega$ in the frequency response function $G(s)$, written as

$$
T_{R}(\omega)=|G(j \omega)|=\sqrt{\frac{1+(2 \zeta \lambda)^{2}}{\left(1-\lambda^{2}\right)^{2}+(2 \zeta \lambda)^{2}}},
$$

where $\lambda=\omega_{0} / \omega, \omega=\sqrt{k^{*} / m}, \zeta=c / 2 \sqrt{k^{*} m}, \omega_{0}$ is the excitation frequency, $\omega$ is the tunable natural frequency of the isolation system, and $\lambda, \zeta$ are the dimensionless frequency and damping ratio, respectively.

3.2. On-Off Semiactive Vibration Controller. In this research, a control strategy based on a robust, reliable control theory, namely, Lyapunov control theory, was applied. The Lyapunov-based control strategy achieved significant reductions in the responses [14]. The dynamic equation for 1-DOF system (4) can be rewritten as

$$
m \ddot{x}+c(\dot{x}-\dot{u})+k_{0}(x-u)=-\Delta k(x-u) .
$$




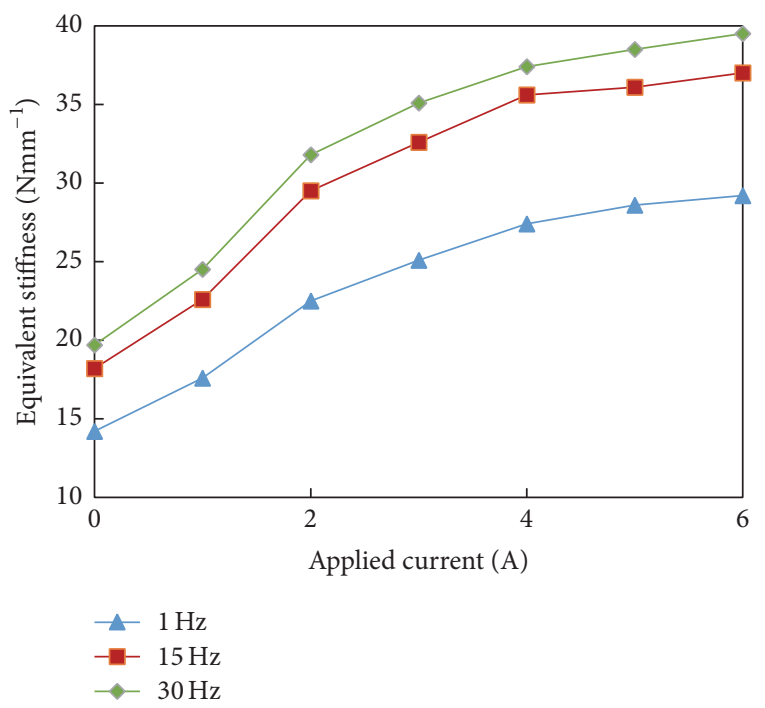

(a)

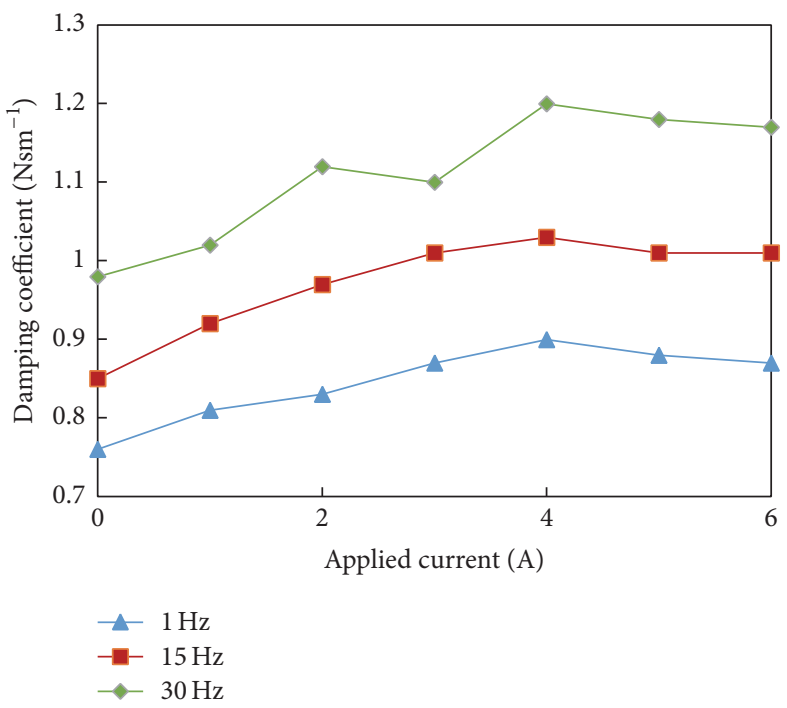

(b)

Figure 7: Stiffness and damping properties versus applied current (magnetic flux density) for different frequencies with excitation amplitude $x_{0}=0.75 \mathrm{~mm}$ : (a) the equivalent stiffness $K$ and (b) the damping coefficient $C$.

For the system given by (7), the Lyapunov function has the following form:

$$
V(x, \dot{x})=\frac{1}{2}\left(\frac{k_{0}}{m}(x-u)^{2}+\dot{x}^{2}\right) .
$$

Therefore, the derivative of the Lyapunov function associated with (7) can be derived as

$$
\begin{aligned}
\dot{V}(x, \dot{x}) & =\frac{k_{0}}{m}(x-u) \dot{x}+\dot{x} \ddot{x} \\
& =\frac{c}{m}(\dot{u}-\dot{x}) \dot{x}-\frac{\Delta k}{m}(x-u) \dot{x} \\
& =-\frac{c}{m} \dot{x}^{2}-\frac{\Delta k}{m}(x-u) \dot{x}+\frac{c}{m} \dot{u} \dot{x} .
\end{aligned}
$$

The following on-off control algorithm to minimize the $\dot{V}(x, \dot{x})$ is proposed as

$$
\Delta k= \begin{cases}0 & \left(k^{*}=k_{0}, I=0 \mathrm{~A}\right) \text { if } x_{r} \dot{x}<0 \\ \Delta k_{\max } & \left(k^{*}=k_{\max }, I=I_{\max }\right) \text { if } x_{r} \dot{x} \geq 0 .\end{cases}
$$

In (10), $k_{0}$ and $k_{\max }$ signify the spring without applied current $(I=0 \mathrm{~A})$ and with maximum applied current $\left(I=I_{\max }\right), x_{r}$ is the relative displacement between the system mass and base, and $\dot{x}$ is the velocity of the system.

3.3. Fuzzy Semiactive Vibration Controller. In the on-off controller, the output choice is either off $(0 \mathrm{~A})$ or on $(4 \mathrm{~A})$. The fast switching of the on-off algorithm causes high acceleration and jerk peaks periodically, thus leading to the degeneration of the overall system quality. The problem can be resolved by using fuzzy logic to soften the fast switching action of the on-off control. The control system based on fuzzy logic control (FLC) analyzes analog input values in terms of logical variables.

As shown in Figure 10, the controller consists of three basic parts: fuzzification, where the continuous input variables are transformed into linguistic variables; fuzzy inference, which consists of fuzzy IF-THEN rules; and defuzzification, which interprets the values for the control variable. Relative displacement $\left(x_{r}\right)$ and velocity $(\dot{x})$ were defined as the controller inputs and were divided into two intervals of linguistic variables: negative (Neg) and positive (Pos). As the control output, tunable stiffness $\left(k^{*}\right)$ was divided into high stiffness (High) and low stiffness (Low). The membership function was depicted in Figure 11. Fuzzy rules play an important role in a fuzzy control system. The rules were based on the on-off semiactive algorithm (10) and they were listed in Table 4. The fuzzy inference of the controller was based on Mamdani's method, which is associated with the max-min composition. The memberships were structured in the shape of a trapezoid. The center of gravity method was adopted as the defuzzification to determine the command stiffness $\left(k^{*}\right)$, which is widely utilized in fuzzy control systems for the Mamdani inference method.

\section{Computer Simulations and Experiments}

4.1. Computer Simulations for Vibration Control of 1-DOF System. Solving nonlinear vibration equations is always a difficult problem. In recent years, there are many analytical and numerical approaches which have been investigated, such as variational iteration method $[15,16]$ and He's energy balance method $[17,18]$. In our research, the mass displacement, $x(t)$ in (7), was determined by the application of He's energy balance method. The method is very effective and convenient, and it does not require linearization. 


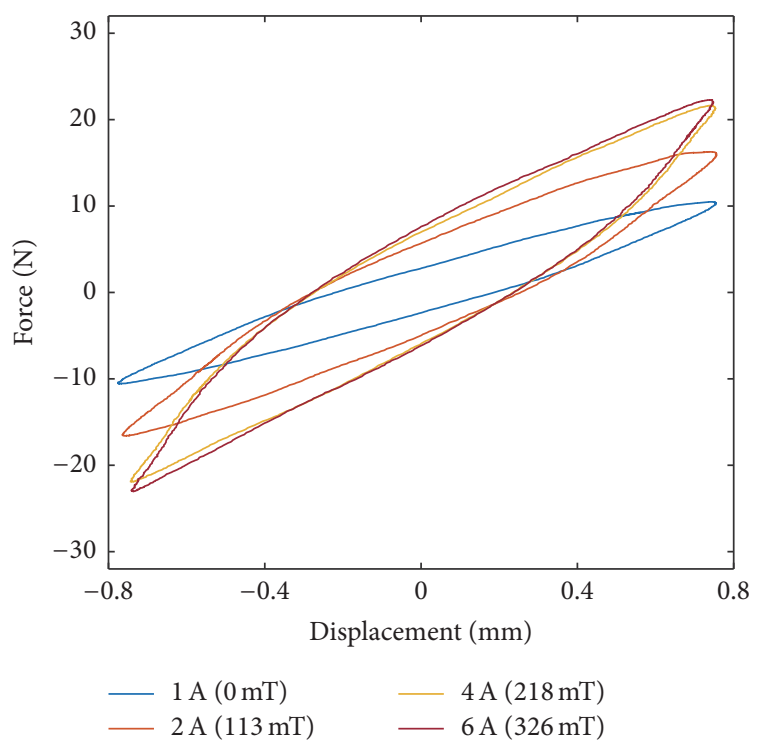

(a)

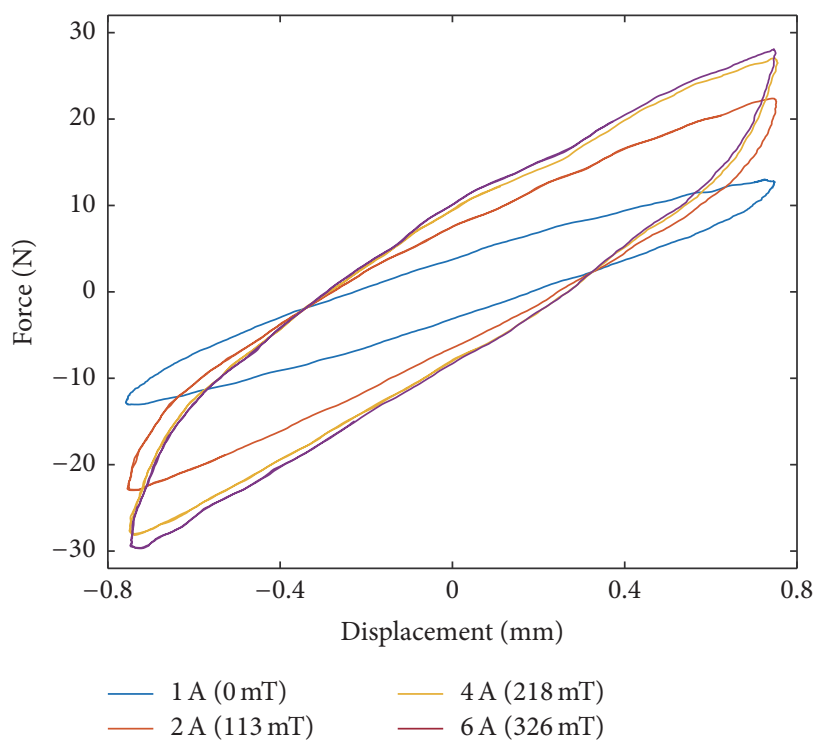

(b)

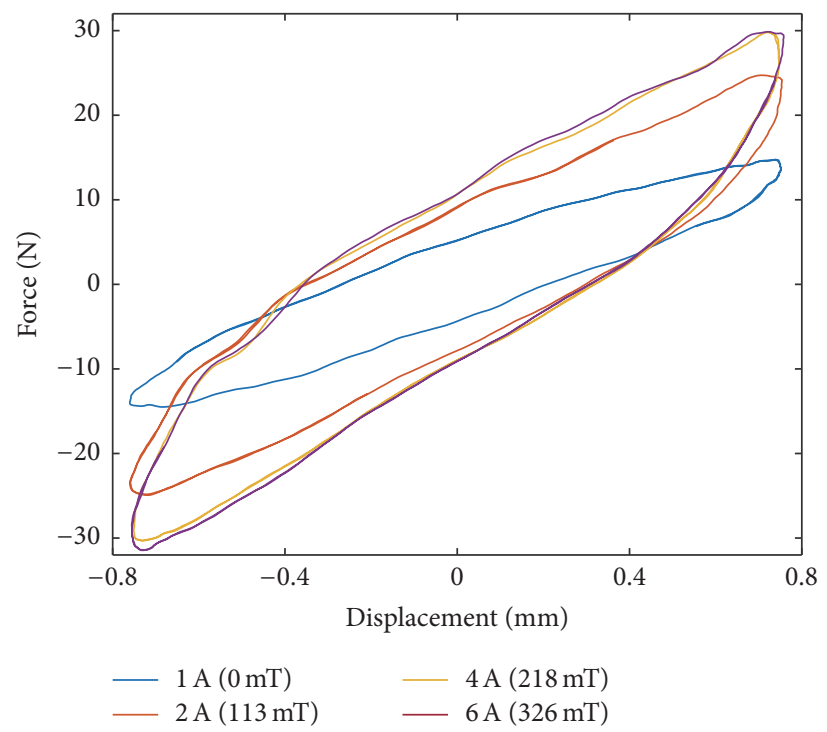

(c)

FIGURE 8: Force-displacement response under different levels of applied current (magnetic flux density) with excitation amplitude $x_{0}=$ $0.75 \mathrm{~mm}$ : (a) $f=1 \mathrm{~Hz}$, (b) $f=15 \mathrm{~Hz}$, and (c) $f=30 \mathrm{~Hz}$.

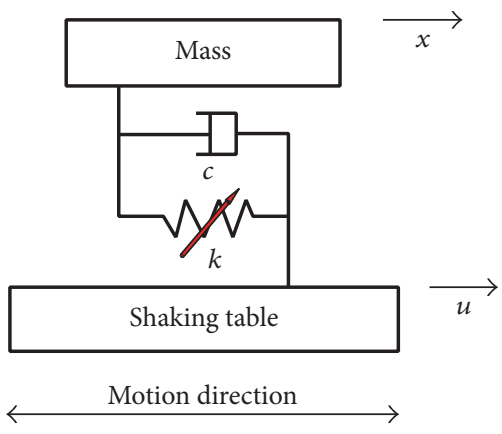

FIGURE 9: Base-excited 1-DOF system.

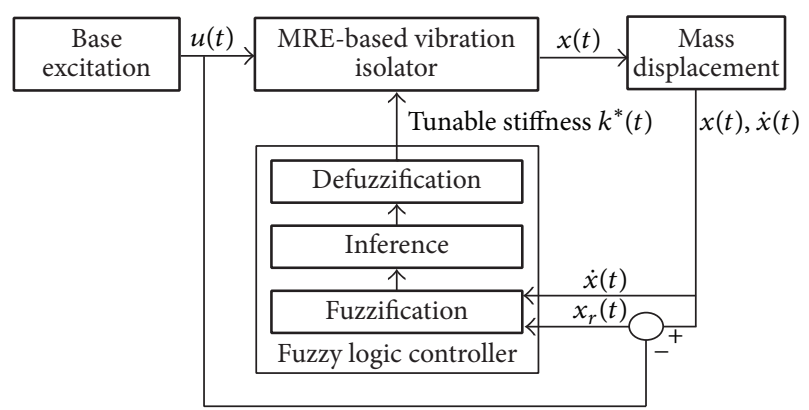

FIGURE 10: Block diagram of fuzzy logic controller for switching MRE stiffness. 

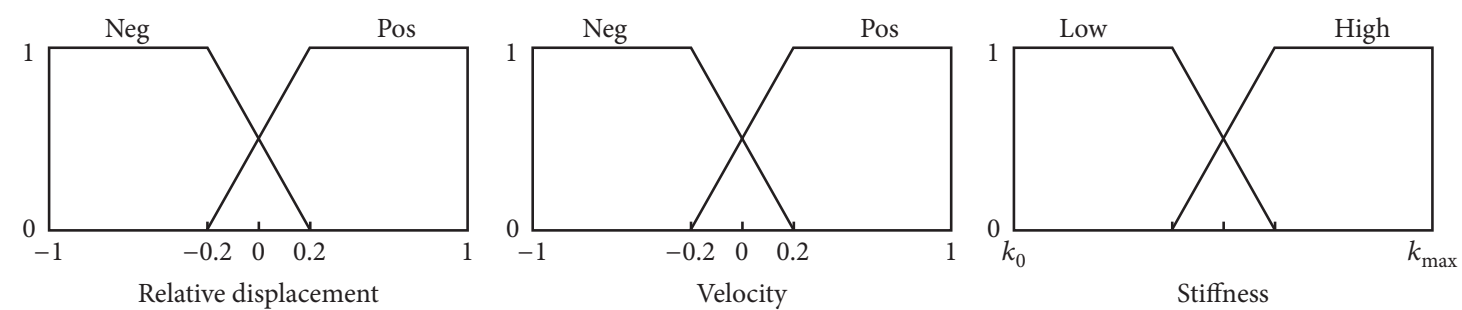

Figure 11: Fuzzy logic membership functions.

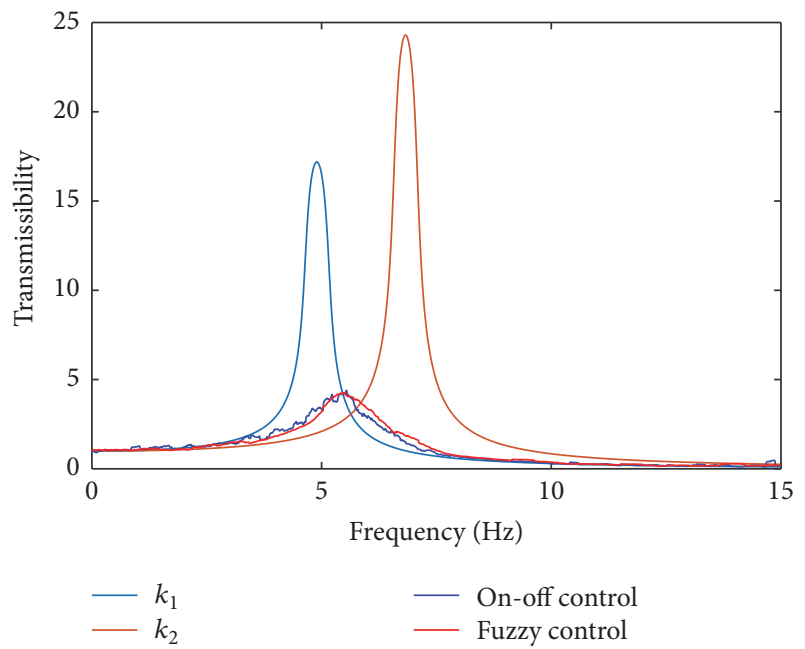

FIGURE 12: Frequency response for 1-DOF system obtained by random excitation.

System responses using passive, on-off semiactive, and fuzzy semiactive control schemes were calculated in order to evaluate the performance of the proposed controller. The model parameters are listed in Table 5, where the actual value was used for the mass, whereas the damping coefficient was set lower than the actual value in order to emphasize the control effect.

The simulation results are shown in Figures 12-15 and listed in Table 6. Figure 12 shows the system frequency response. In this case, the frequency of the random base excitation varied between $1 \mathrm{~Hz}$ and $15 \mathrm{~Hz}$. The figure shows that the displacement transmissibility was significantly reduced in both the on-off and fuzzy semiactive controls. An insignificant difference was found in the displacement transmissibility curves between these two control strategies. Figure 13 describes the displacement response of the mass under random excitation. Mass vibration was significantly suppressed by both the on-off and fuzzy semiactive controls. The on-off semiactive control performed slightly better than the fuzzy semiactive control.

The RMS and maximum values of the payload response are listed in Table 6. The values in parentheses represent the ratio of the values to those obtained for the passive-off case with minimum stiffness $k_{0}$. The RMS ratios of the displacement response in the fuzzy semiactive control decreased significantly to 0.45 , whereas the values were 1 and 1.43 for
TABle 4: Fuzzy logic rules.

\begin{tabular}{lcc}
\hline Relative displacement/velocity & Neg & Pos \\
\hline Neg & High & Low \\
Pos & Low & High \\
Fuzzy inference & \multicolumn{2}{c}{ Mamdani type } \\
Defuzzification & \multicolumn{2}{c}{ Center of gravity } \\
\hline
\end{tabular}

TABLE 5: Parameters used in simulation.

\begin{tabular}{lc}
\hline Damping coefficient & $1 \mathrm{Nsm}^{-1}$ \\
Mass & $1.138 \mathrm{~kg}^{-1}$ \\
Spring constant (minimum, $k_{0}$ ) & $974.5 \mathrm{Nm}^{-1}$ \\
Spring constant (maximum, $k_{\max }$ ) & $1948.9 \mathrm{Nm}^{-1}$ \\
Base excitation amplitude & $2 \mathrm{~mm}$ \\
\hline
\end{tabular}

the passive control with minimum and maximum stiffness, respectively. In addition, the acceleration RMS values also decreased in the case of the fuzzy semiactive control. The maximum displacement and acceleration responses when using the fuzzy semiactive control were much smaller than the response of the passive control cases. It is obvious that the energy consumption in the fuzzy semiactive control is much smaller than the energy required in the case of the passive-on control. The overall performance of the system that uses the fuzzy semiactive control surpassed that of the passive systems. The on-off semiactive system performed slightly better than the fuzzy semiactive system; the RMS ratios were 0.41 and 0.43 for the on-off and fuzzy controls, respectively. However, peak acceleration in the case of the onoff semiactive control was higher than in the case of the fuzzy semiactive control, as shown in Figure 14.

Figure 15 represents the required electric current for both the on-off and fuzzy semiactive controls. Based on the stiffness values $k_{0}$ and $k_{\max }$ obtained for the applied currents of $0 \mathrm{~A}$ and $4 \mathrm{~A}$, the stiffness change within this range was assumed to be linear. The fast switching action of the crisp controller was softened by the fuzzy algorithm, and the current transition state became smoother. Consequently, the acceleration peaks were reduced when using the fuzzy algorithm. The figure shows that the fuzzy algorithm offered slight changes in the applied current at the frequent switching points of displacement $(x)$ or velocity $(\dot{x})$, for example, at points between $2.8 \mathrm{~s}$ to $3.2 \mathrm{~s}$. In contrast, the on-off algorithm operated in high frequency. Furthermore, the actual 


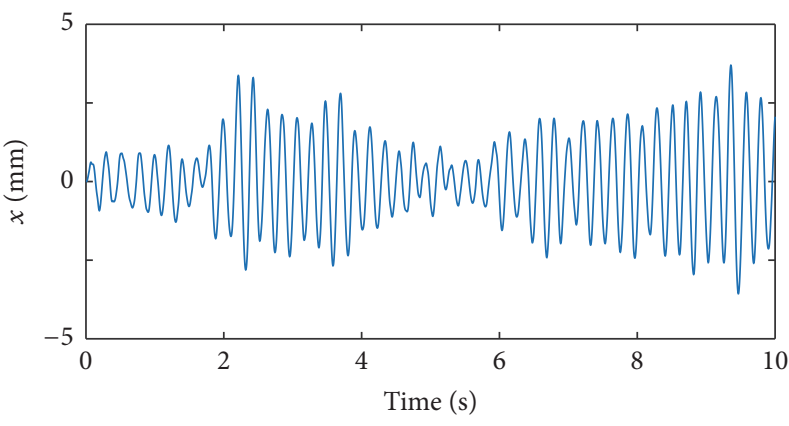

(a)

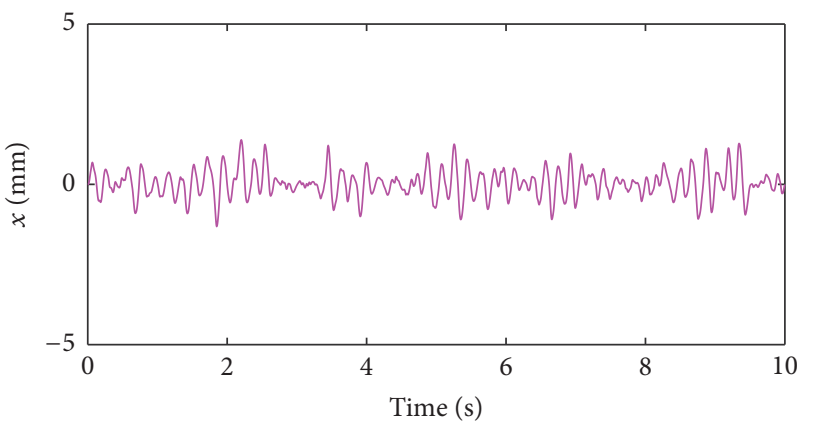

(c)

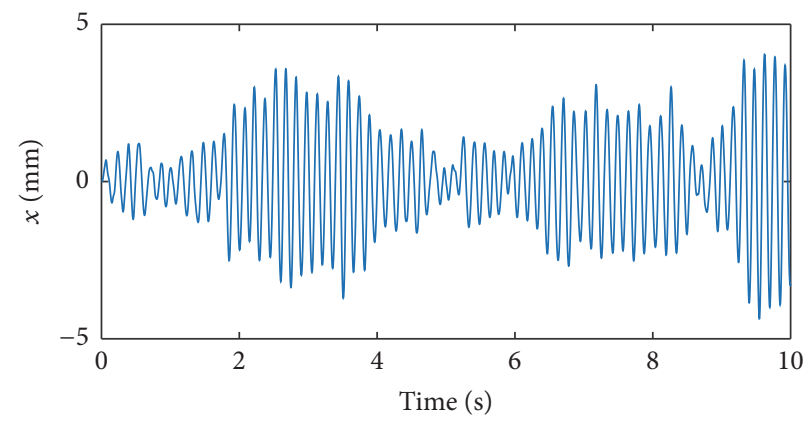

(b)

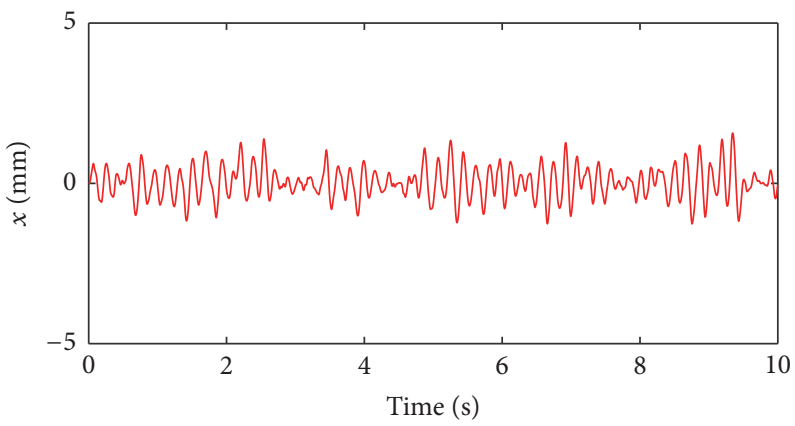

(d)

FIGURE 13: Displacement response by random excitation: (a) the passive $\left(k^{*}=k_{0}\right)$, (b) the passive $\left(k^{*}=\mathrm{k}_{\max }\right)$, (c) the on-off semiactive control, and (d) the fuzzy semiactive control.

TABLE 6: Displacement and acceleration values of response to random excitation (simulation).

\begin{tabular}{lcccc}
\hline & RMS values & \multicolumn{2}{c}{ Maximum values } \\
& $x[\mathrm{~mm}]$ & $\ddot{x}\left[\mathrm{~ms}^{-2}\right]$ & $x[\mathrm{~mm}]$ & $2.95(1)$ \\
\hline Passive-off $\left(k_{0}\right)$ & $1.07(1)$ & $0.99(1)$ & $4.04(1.37)$ & $2.62(1)$ \\
Passive-on $\left(k_{\max }\right)$ & $1.53(1.43)$ & $2.71(2.73)$ & $1.38(0.46)$ & $2.5(3.24)$ \\
On-off semiactive & $0.44(0.41)$ & $0.75(0.76)$ & $1.56(0.53)$ & $2.99(1.14)$ \\
Fuzzy semiactive & $0.49(0.43)$ & $0.80(0.78)$ & & \\
\hline
\end{tabular}

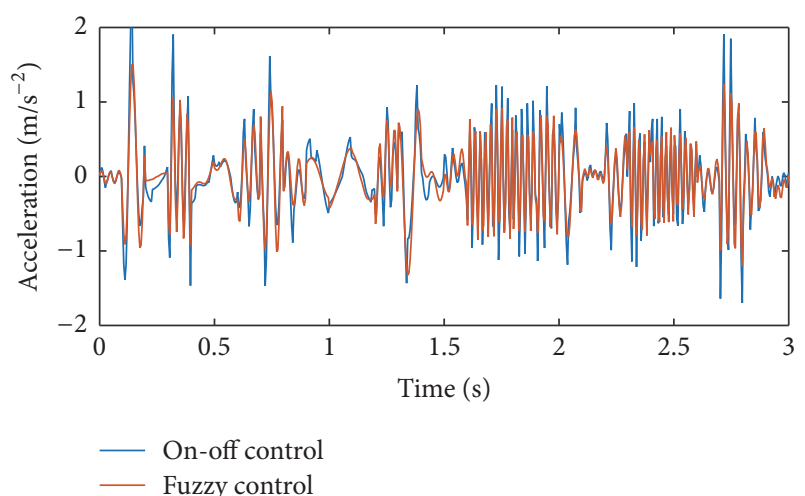

FIGURE 14: Acceleration response to random excitation for on-off semiactive control and for fuzzy semiactive control.

current provided for the inductor requires transient time [19]. Therefore, the fuzzy algorithm adapted more effectively to

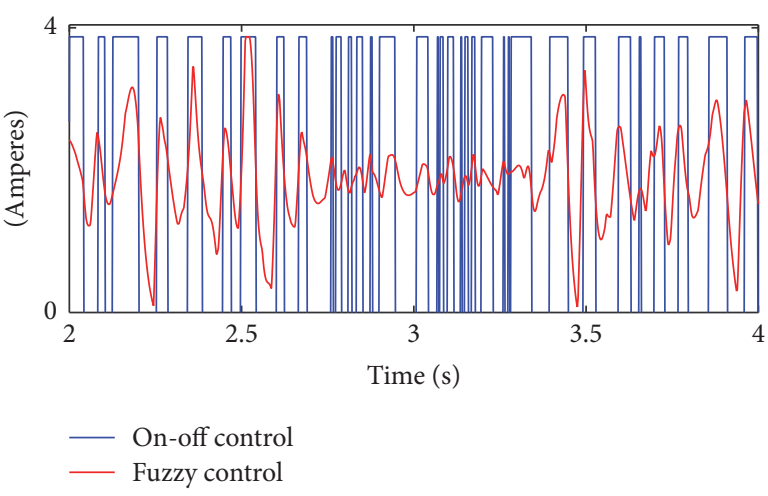

FIgURE 15: Applied current in on-off semiactive and fuzzy semiactive controls.

such current properties. It is demonstrated that the fuzzy semiactive control system is effective in reducing structural 


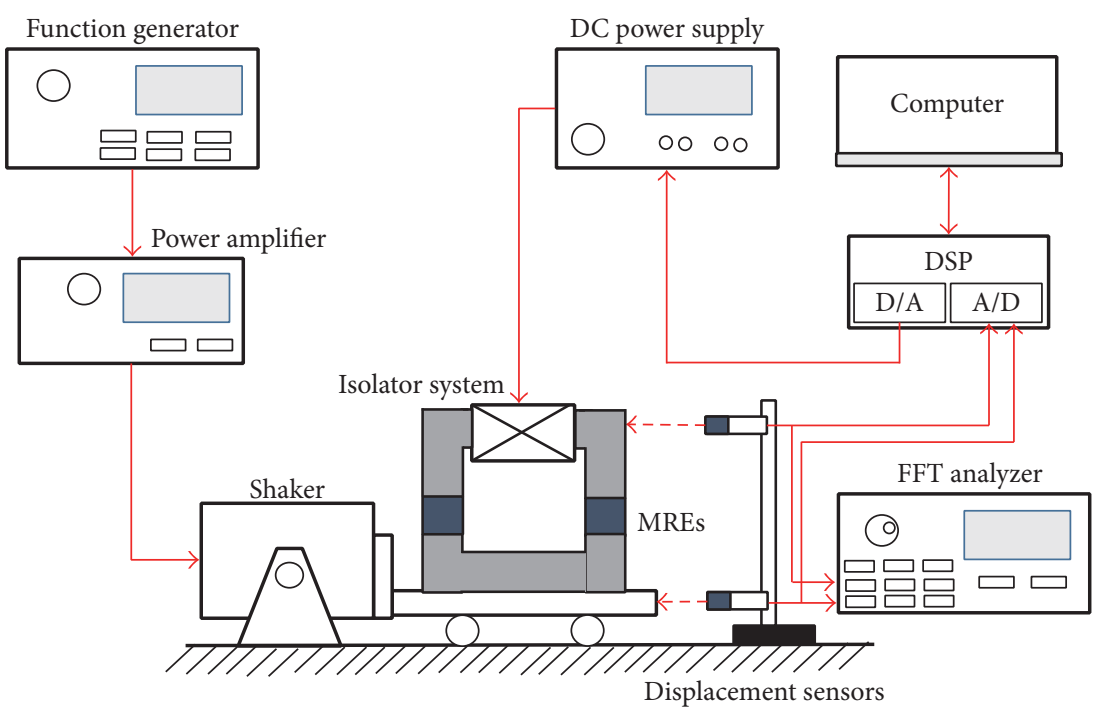

(a)

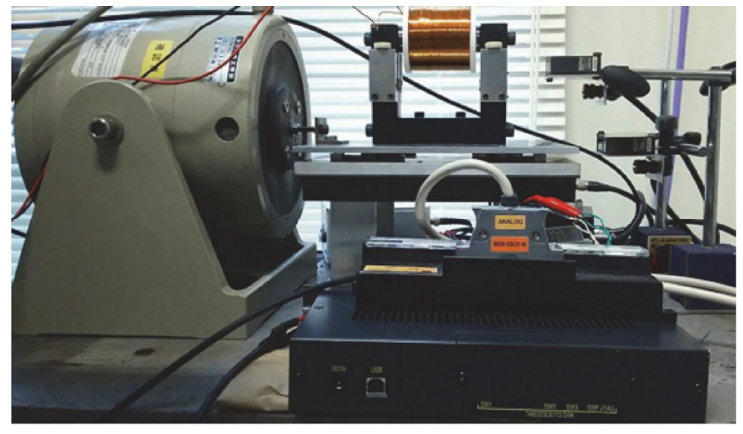

(a)

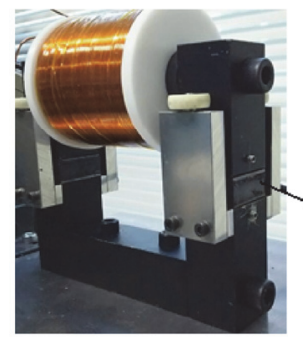

(b)

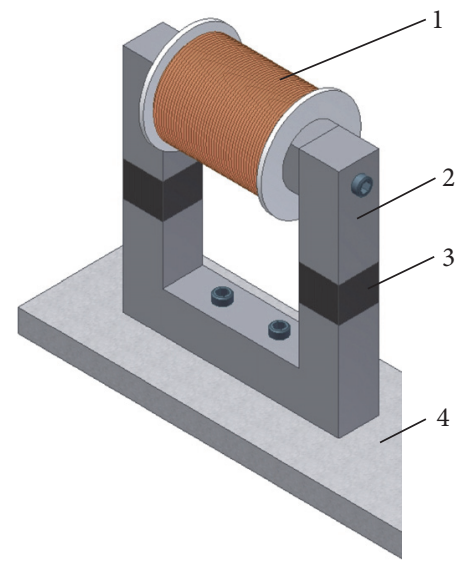

(b)

FIGURE 16: Experiment setup for MRE-based VI: (a) the schematic diagram and (b) the 3D sketch for MRE isolator system: 1, magnetic excitation coil; 2 , magnetic conductor; 3 , MRE; 4 , base.

FIgURE 17: Photos for (a) experiment setup, (b) isolator system, and (c) MRE sample.

responses, especially in the case of random excitations and high frequency.

4.2. Experiment. An experiment was conducted to assess the effectiveness of the MRE isolator using the experimental setup shown in Figure 16. A photo of the experimental apparatus is also shown in Figure 17. The experimental parameters are listed in Table 7 . In the experiment, the isolator that incorporated MRE with $40 \mathrm{vol} \%$ iron content was used. A pair of fabricated MRE samples was fixed between the iron cores of the electromagnet as the variable spring. The lower core was fixed on the base, and the upper was allowed to move in the horizontal direction. The upper core and inductor were assumed to work together as the mass. Two laser displacement sensors were used to measure the displacements of the base and mass. The analog displacement signals were sent to a digital signal processor (TMS320C6713 DSK Board) controller as the input signals.
TABLE 7: Parameters used in experiment.

\begin{tabular}{lc}
\hline MRE type & Anisotropic MRE, 40 vol\% \\
Number of MREs & 2 \\
Dimension of MREs & $25 \times 25 \times 10 \mathrm{~mm}$ \\
Mass & $1.138 \mathrm{~kg}$ \\
Minimum applied current & $0 \mathrm{~A}$ \\
Maximum applied current & $4 \mathrm{~A}$ \\
Frequency excitation & $1-50 \mathrm{~Hz}$ \\
Base excitation amplitude & $1 \mathrm{~mm}$ \\
Excitation type & Random \\
\hline
\end{tabular}

Based on the control algorithms defined by (10) for the on-off algorithm and Table 1 for the fuzzy rules, the output signal was calculated and sent to the direct current (DC) power supply to drive the inductor. The base excitation was 


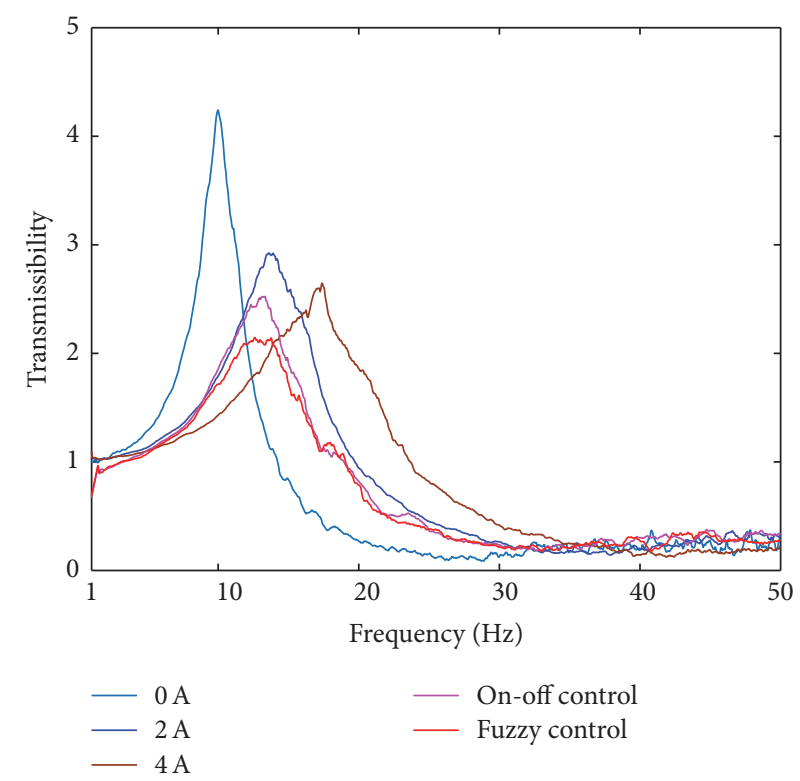

FIGURE 18: Frequency response by random excitation (experiment).

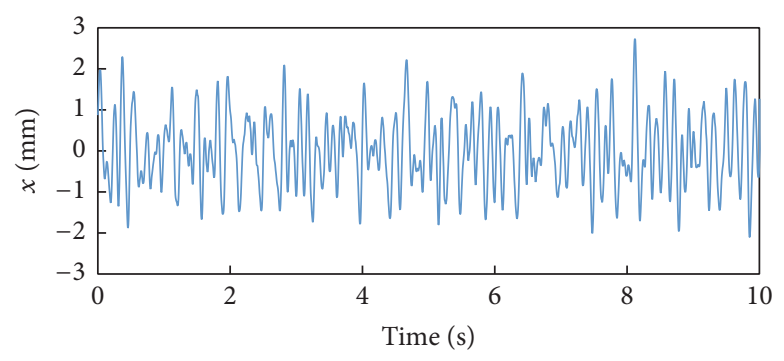

(a)

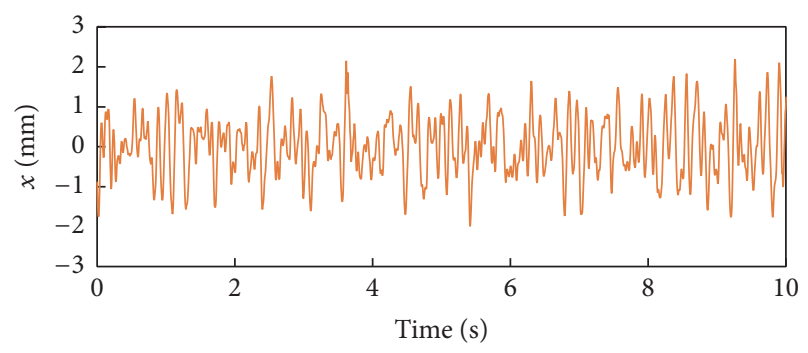

(c)

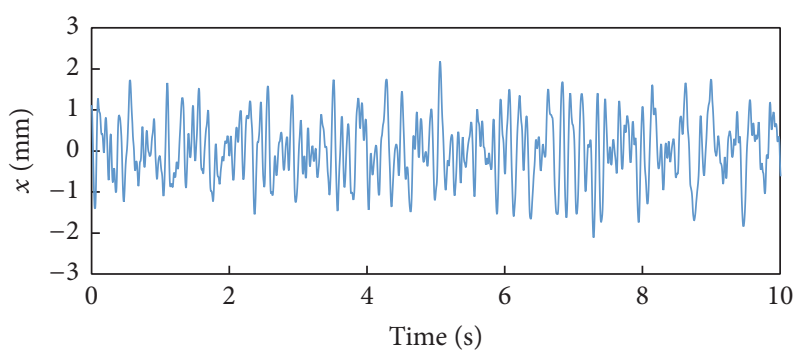

(b)

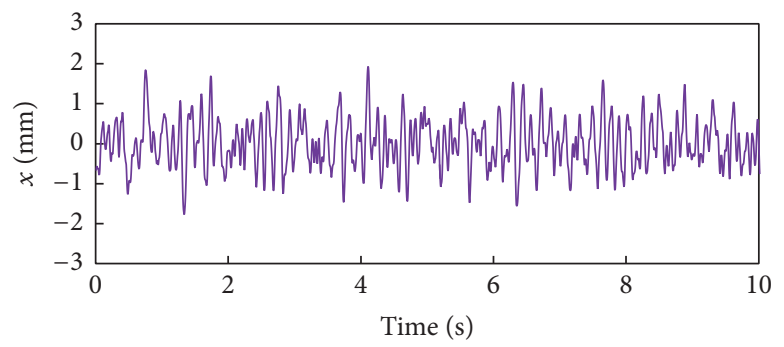

(d)

FIGURE 19: Displacement response to random excitation (experiment): (a) passive-off (0 A), (b) passive-on (4 A), (c) the on-off semiactive control, and (d) the fuzzy semiactive control.

induced by the exciter driven by the power amplifier, and the power amplifier received the base excitation signal from the function generator.

The experimental results are shown in Figures 18 and 19 and listed in Table 8. Figure 18(a) shows the displacement transmissibility curves for the white-noise random excitation of the cutoff frequency $50 \mathrm{~Hz}$. The results were compared among three passive systems (the constant applied current values were $0 \mathrm{~A}, 2 \mathrm{~A}$, and $4 \mathrm{~A}$, respectively) and two semiactively controlled systems that used the two types of controller described previously. The transmissibility was small and almost the same when the systems worked in the high-frequency region (over $30 \mathrm{~Hz}$ ). In contrast, the transmissibility was high and different for the different control strategies in the low-frequency region. The passive system with zero applied current had the smallest natural frequency and highest peak of transmissibility. The passive system with $4 \mathrm{~A}$-applied current had the largest natural frequency and 
TABLE 8: Displacement and acceleration values of response to random excitation (experiment).

\begin{tabular}{lcccc}
\hline & & RMS values & \multicolumn{2}{c}{ Maximum values } \\
& $x[\mathrm{~mm}]$ & $\ddot{x}\left[\mathrm{~ms}^{-2}\right]$ & $x[\mathrm{~mm}]$ & $3.4(1)$ \\
Passive-off $(I=0 \mathrm{~A})$ & $1.08(1)$ & $1.03(1)$ & $3.18(0.93)$ & $6.24(1)$ \\
Passive-on $(I=4 \mathrm{~A})$ & $0.96(0.88)$ & $1.26(1.22)$ & $2.6(0.76)$ & $4.98(0.79)$ \\
On-off semiactive & $0.85(0.78)$ & $0.92(0.89)$ & $2.26(0.66)$ & $4.52(0.72)$ \\
Fuzzy semiactive & $0.75(0.69)$ & $0.82(0.79)$ & & $3.95(0.63)$ \\
\hline
\end{tabular}

lowest peak of transmissibility. These results are consistent with the MRE material properties mentioned in Section 2: the stiffness and loss damping coefficient for MRE increased when the applied current increased accordingly. Noticeably, transmissibly was reduced significantly in the low frequency when the semiactive controllers were used. The performance was found to be more effective in the case of using the fuzzy algorithm than in the case of using the on-off algorithm.

Figure 19 shows the displacement response of the mass under different control strategies. The mass vibration was remarkably suppressed when the semiactive control algorithms were applied. The fuzzy algorithm worked better than the on-off algorithm. The RMS and maximum values of the mass are listed in Table 8; both values were reduced significantly using these controllers. The fuzzy control performed better than the on-off control. The reduction rates were $31 \%$ and $34 \%$ for the RMS and maximum displacement values, respectively. The acceleration RMS and maximum acceleration values also decreased in the case of the fuzzy semiactive control by $21 \%$ and $37 \%$, respectively.

From Figures 13, 14, and 15 (simulated results) and Figures 18 and 19 (experimental results), the effectiveness of fuzzy semiactive strategy can be explained by its operation mechanism. MRE-based isolator is used to produce external force $\left(F=x_{r} \times \Delta k\right)$ on structure in order to absorb vibration energy in response to a desirable applied current. In the case of large displacement, if the system tends to leave the equilibrium position $\left(x_{r} \dot{x}<0\right)$, both the isolator with on-off semiactive controller and the isolator with fuzzy semiactive controller operate with the same mechanism. These isolators produce maximum force $\left(F=\Delta k_{\max } x_{r}\right)$ to absorb vibration as much as possible. The effectiveness of these two controllers is the same in this situation. In contrast, if the system tends to return to the equilibrium position $\left(x_{r} \dot{x} \geq 0\right)$, the isolator with on-off semiactive controller does not produce external force $(F=0, I=0)$; then the system returns to equilibrium position freely. Consequently, the system will overshoot out of equilibrium position because of system inertia, especially in the case of high acceleration. The isolator with fuzzy semiactive control produces a sufficient force to restrict this overshoot. This sufficient force depends on fuzzification and inference processing based on human knowledges, experiences, and observations in many cases of studies. As a result, fuzzy algorithm is more effective than onoff algorithm in this situation, and it helps structure reaching nearly their critically damped point. In the case of small displacement, the isolator with on-off controller produces either maximum or minimum force around equilibrium, which causes chattering or an underdamped vibration. However, the isolator with fuzzy semiactive controller produces a sufficient force. Consequently, fuzzy strategy is also more effective in this case.

\section{Conclusions}

In this study, the fuzzy semiactive control strategy was proposed for MRE stiffness switching used as VI. The dynamic viscoelastic characteristics of MREs-based isolator were presented. The stiffness was controlled by controlling electric current applied to an electromagnet. The algorithm was developed with the aim of switching MRE stiffness smoothly in comparison with the on-off type algorithm. The real-time vibration control performance of the fuzzy semiactive isolator system was evaluated by both computer simulation and experiment for a single DOF system. The performance was compared with that of passive systems and a system with on-off type controller. The results showed that the fuzzy semiactive control provided better performance than its counterparts, not only by reducing chatter, but also by conserving the electrical energy of the device. When tuned appropriately, the fuzzy semiactive controller is capable of improving the response characteristics and efficiency of semiactive type systems.

\section{Nomenclature}

$K: \quad$ Equivalent stiffness of $\operatorname{MRE}(\mathrm{N} / \mathrm{mm})$

$C: \quad$ Damping coefficient of $\operatorname{MRE}(\mathrm{Ns} / \mathrm{m})$

E: $\quad$ Dissipated energy $(\mathrm{Nmm})$

$F$ : $\quad$ Viscoelastic force $(\mathrm{N})$

$F_{0}: \quad$ Viscoelastic force amplitude $(\mathrm{N})$

$x$ : $\quad$ Displacement $(\mathrm{mm})$

$u: \quad$ Base excitation $(\mathrm{mm})$

$m: \quad$ Mass of 1-DOF system $(\mathrm{kg})$

$c: \quad$ Damping coefficient of 1-DOF system (Ns/m)

$k^{*}: \quad$ Tunable stiffness of $1-D O F$ system $(\mathrm{N} / \mathrm{mm})$

$k_{0}$ : $\quad$ Minimum stiffness of 1-DOF system $(\mathrm{N} / \mathrm{mm})$

$k_{\text {max }}$ : Maximum stiffness of 1-DOF system (N/mm)

$\Delta k: \quad$ Increment of stiffness of 1-DOF system $(\mathrm{N} / \mathrm{mm})$

$G(s)$ : Laplace transfer function

$T_{R}(\omega)$ : Displacement transmissibility

$\lambda: \quad$ Dimensionless frequency

$\zeta$ : $\quad$ Damping ratio

$\omega_{0}: \quad$ Excitation frequency $(\mathrm{rad} / \mathrm{s})$

$\omega: \quad$ Tunable natural frequency $(\mathrm{rad} / \mathrm{s})$

I: $\quad$ Applied current (A) 
$I_{\min }: \quad$ Minimum applied current $(0 \mathrm{~A})$

$I_{\max }: \quad$ Maximum applied current $(4 \mathrm{~A})$

$V(x, \dot{x})$ : Lyapunov function.

\section{Competing Interests}

The authors declare that they have no competing interests.

\section{Acknowledgments}

The work was supported by JSPS KAKENHI, Grant-in-Aid for Scientific Research (B), Grant no. 15H03936. The support is gratefully acknowledged.

\section{References}

[1] J. D. Carlson and M. R. Jolly, "MR fluid, foam and elastomer devices," Mechatronics, vol. 10, no. 4, pp. 555-569, 2000.

[2] K. M. Popp, M. Kröger, W. Li, X. Z. Zhang, and P. B. Kosasih, "MRE properties under shear and squeeze modes and applications," Journal of Intelligent Material Systems and Structures, vol. 21, no. 15, pp. 1471-1477, 2010.

[3] Y. Li, J. Li, W. Li, and H. Du, "A state-of-the-art review on magnetorheological elastomer devices," Smart Materials and Structures, vol. 23, no. 12, pp. 1-24, 2014.

[4] J. M. Ginder, M. E. Nichols, L. D. Elie, and J. L. Tardiff, "Magnetorheological elastomers: properties and applications," in Proceedings of SPIE the Smart Structures and Materials on Smart Materials Technologies, pp. 131-138, SPIE, Newport Beach,Calif, USA, March 1999.

[5] S. Opie and W. Yim, "Design and control of a real-time variable modulus vibration isolator," Journal of Intelligent Material Systems and Structures, vol. 22, no. 2, pp. 113-125, 2011.

[6] T. Komatsuzaki and Y. Iwata, "Design of a real-time adaptively tuned dynamic vibration absorber with a variable stiffness property using magnetorheological elastomer," Shock and Vibration, vol. 2015, Article ID 676508, 11 pages, 2015.

[7] G. J. Liao, X.-L. Gong, S. H. Xuan, C. J. Kang, and L. H. Zong, "Development of a real-time tunable stiffness and damping vibration isolator based on magnetorheological elastomer," Journal of Intelligent Material Systems and Structures, vol. 23, no. 1, pp. 25-33, 2012.

[8] F. Yi, S. J. Dyke, J. M. Caicedo, and J. D. Carlson, "Experimental verification of multiinput seismic control strategies for smart dampers," Journal of Engineering Mechanics, vol. 127, no. 11, pp. 1152-1164, 2001.

[9] Y. Wang and S. Dyke, "Modal-based LQG for smart base isolation system design in seismic response control," Structural Control and Health Monitoring, vol. 20, no. 5, pp. 753-768, 2013.

[10] M. D. Symans and S. W. Kelly, "Fuzzy logic control of bridge structures using intelligent semi-active seismic isolation systems," Earthquake Engineering \& Structural Dynamics, vol. 28, no. 1, pp. 37-60, 1999.

[11] X. Wang and F. Gordaninejad, "Lyapunov-based control of a bridge using magneto-rheological fluid dampers," Journal of Intelligent Material Systems and Structures, vol. 13, no. 7-8, pp. 415-419, 2002.

[12] Y.-J. Cha and A. K. Agrawal, "Velocity based semi-active turboLyapunov control algorithms for seismically excited nonlinear smart structures," Structural Control and Health Monitoring, vol. 20, no. 6, pp. 1043-1056, 2013.
[13] M. Berg, "A non-linear rubber spring model for rail vehicle dynamics analysis," Vehicle System Dynamics, vol. 30, no. 3-4, pp. 197-212, 1998.

[14] L. M. Jansen and S. J. Dyke, "Semiactive control strategies for MR dampers: comparative study," Journal of Engineering Mechanics, vol. 126, no. 8, pp. 795-803, 2000.

[15] M. Rafei, D. D. Ganji, H. Daniali, and H. Pashaei, "The variational iteration method for nonlinear oscillators with discontinuities," Journal of Sound and Vibration, vol. 305, no. 4-5, pp. 614-620, 2007.

[16] M. Bayat, M. Bayat, and I. Pakar, "Nonlinear vibration of an electrostatically actuated microbeam," Latin American Journal of Solids and Structures, vol. 11, no. 3, pp. 534-544, 2014.

[17] I. Mehdipour, D. D. Ganji, and M. Mozaffari, "Application of the energy balance method to nonlinear vibrating equations," Current Applied Physics, vol. 10, no. 1, pp. 104-112, 2010.

[18] S. S. Ganji, D. D. Ganji, Z. Z. Ganji, and S. Karimpour, "Periodic solution for strongly nonlinear vibration systems by He's energy balance method," Acta Applicandae Mathematicae, vol. 106, no. 1, pp. 79-92, 2009.

[19] Y.-J. Cha, A. K. Agrawal, and S. J. Dyke, "Time delay effects on large-scale MR damper based semi-active control strategies," Smart Materials and Structures, vol. 22, no. 1, Article ID 015011, 2013. 


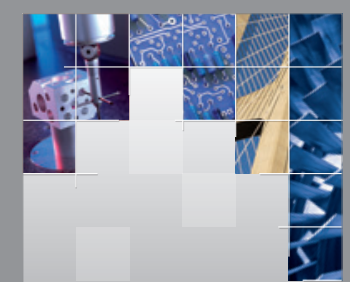

\section{Enfincering}
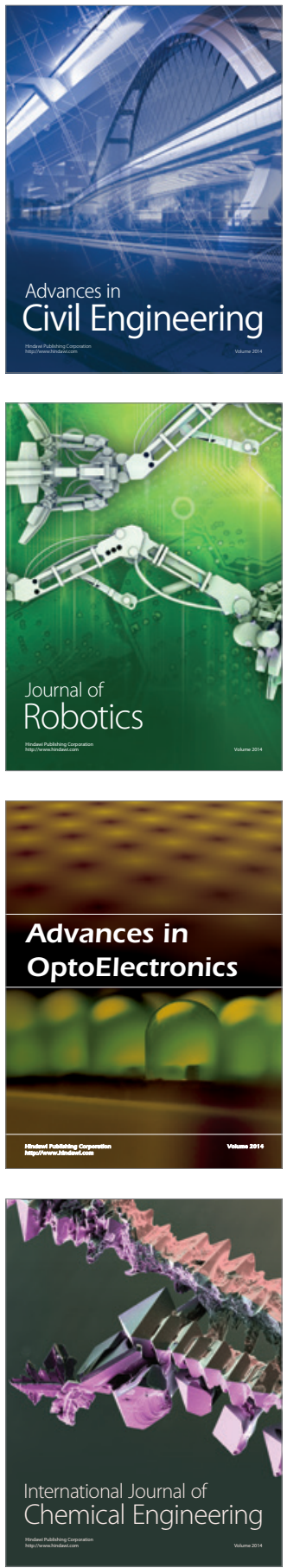

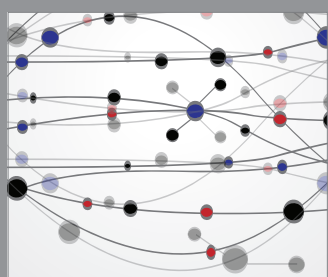

The Scientific World Journal

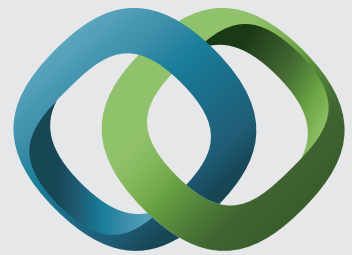

\section{Hindawi}

Submit your manuscripts at

https://www.hindawi.com
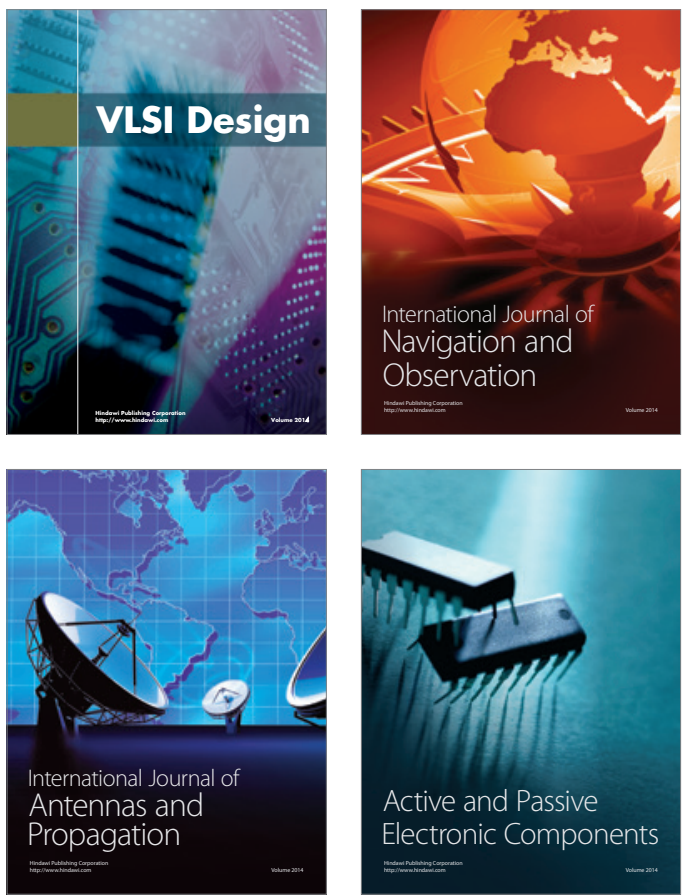
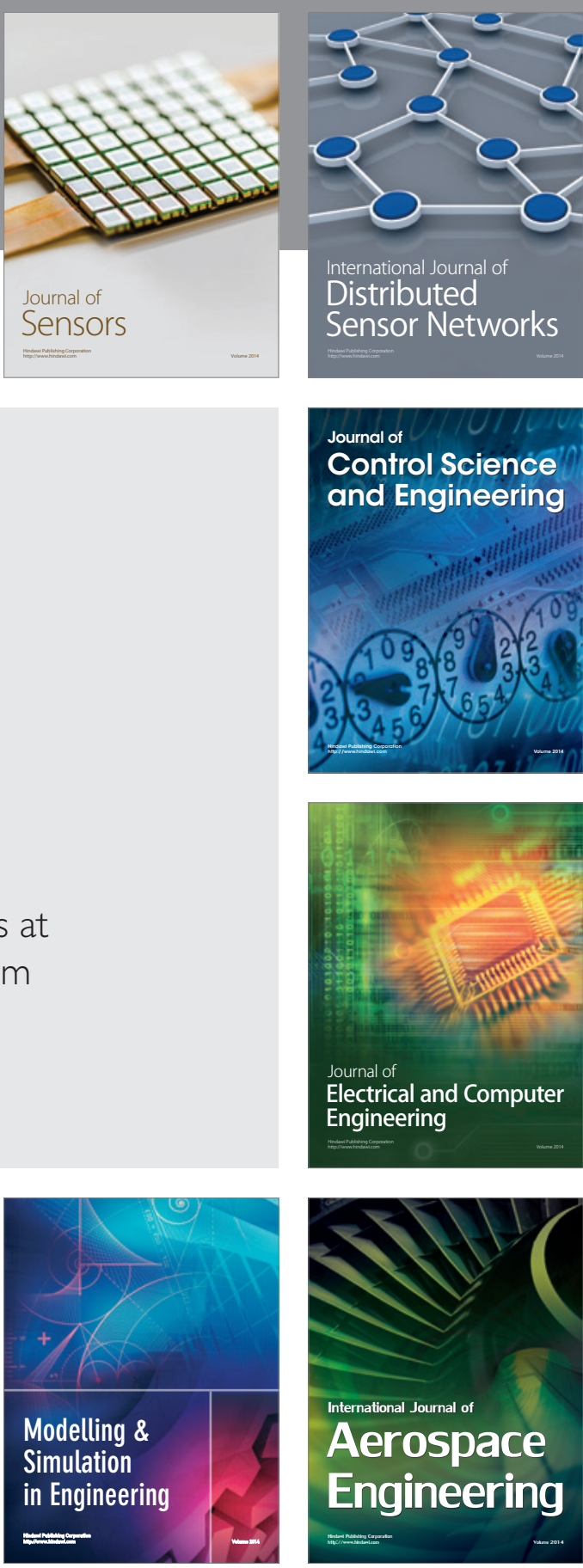

International Journal of

Distributed

Sensor Networks

$-$

Joumal of

Control Science

and Engineering
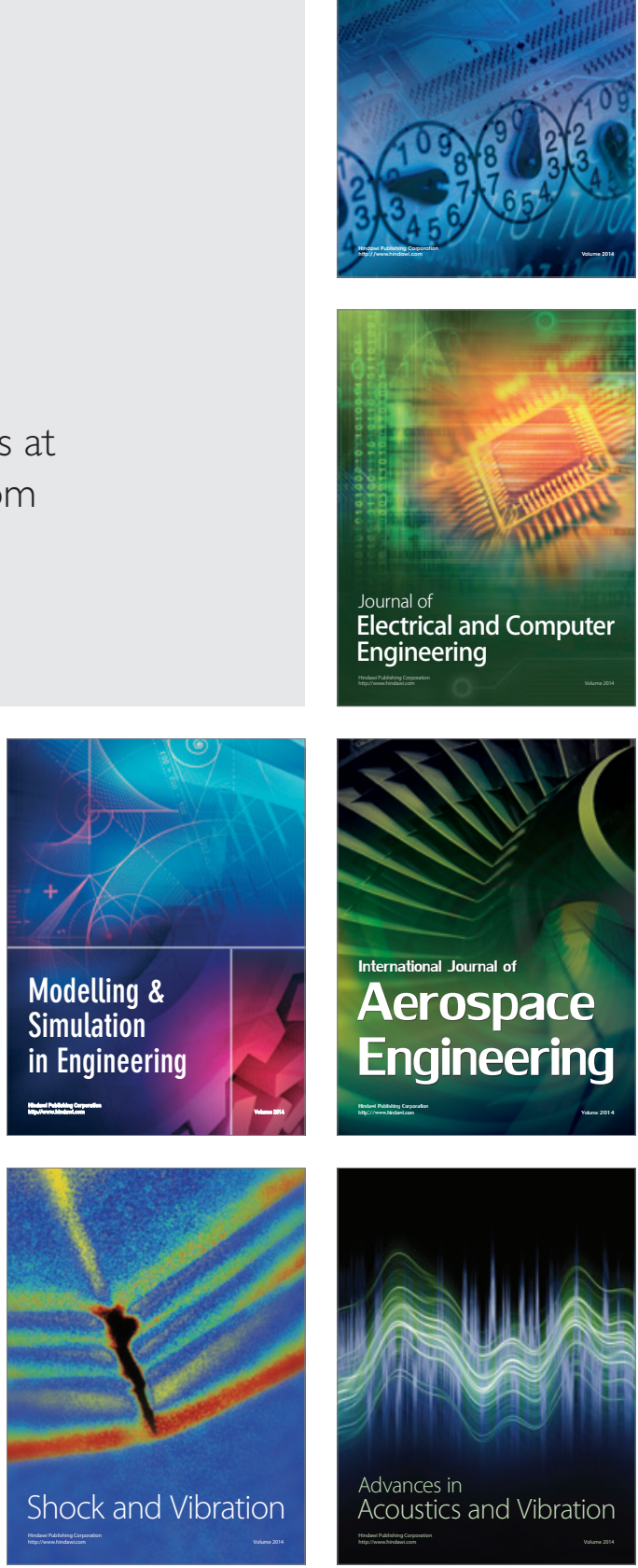